\title{
Cardiovascular Development and the Colonizing Cardiac Neural Crest Lineage
}

\author{
Paige Snider, Michael Olaopa, Anthony B. Firulli, and Simon J. Conway* \\ Cardiovascular Development Group, Herman B Wells Center for Pediatric Research, \\ Indiana University School of Medicine, Indianapolis, IN 46202. \\ E-mail: siconway@iupui.edu
}

Received November 27, 2006; Revised May 17, 2007; Accepted May 25, 2007; Published July 3, 2007

\begin{abstract}
Although it is well established that transgenic manipulation of mammalian neural crestrelated gene expression and microsurgical removal of premigratory chicken and Xenopus embryonic cardiac neural crest progenitors results in a wide spectrum of both structural and functional congenital heart defects, the actual functional mechanism of the cardiac neural crest cells within the heart is poorly understood. Neural crest cell migration and appropriate colonization of the pharyngeal arches and outflow tract septum is thought to be highly dependent on genes that regulate cell-autonomous polarized movement (i.e., gap junctions, cadherins, and noncanonical Wnt1 pathway regulators). Once the migratory cardiac neural crest subpopulation finally reaches the heart, they have traditionally been thought to participate in septation of the common outflow tract into separate aortic and pulmonary arteries. However, several studies have suggested these colonizing neural crest cells may also play additional unexpected roles during cardiovascular development and may even contribute to a crest-derived stem cell population. Studies in both mice and chick suggest they can also enter the heart from the venous inflow as well as the usual arterial outflow region, and may contribute to the adult semilunar and atrioventricular valves as well as part of the cardiac conduction system. Furthermore, although they are not usually thought to give rise to the cardiomyocyte lineage, neural crest cells in the zebrafish (Danio rerio) can contribute to the myocardium and may have different functions in a species-dependent context. Intriguingly, both ablation of chick and Xenopus premigratory neural crest cells, and a transgenic deletion of mouse neural crest cell migration or disruption of the normal mammalian neural crest gene expression profiles, disrupts ventral myocardial function and/or cardiomyocyte proliferation. Combined, this suggests that either the cardiac neural crest secrete factor/s that regulate myocardial proliferation, can signal to the epicardium to subsequently secrete a growth factor/s, or may even contribute directly to the heart. Although there are species differences between mouse, chick, and Xenopus during cardiac neural crest cell morphogenesis, recent data suggest mouse and chick are more similar to each other than to the zebrafish neural crest cell lineage. Several groups have used the genetically defined Pax3 (splotch) mutant mice model to address the role of the cardiac neural crest lineage. Here we review the current literature, the neural crest-related role of the Pax 3 transcription factor, and discuss potential function/s of cardiac neural crest-derived cells during cardiovascular developmental remodeling.
\end{abstract}


KEYWORDS: cardiac neural crest, migration, pharyngeal arches, Pax3, Wnt1, aortic arch arteries, vascular remodeling, outflow tract, endocardial cushions, cardiac septation, myocardial failure, Cre/loxP, lineage mapping, stem cells

\section{INTRODUCTION}

Neural crest cells (NC) are a multipotent and transient migratory embryonic lineage that ultimately gives rise to an enormous array of different cell types, tissues, and organs[1]. The NC are required at different developmental stages for normal development of diverse organ systems, such as the peripheral and enteric nervous systems, facial skeleton, melanocytes, and cardiac outflow tract (OFT) septum. NC induction occurs in the neural folds at the dorsal aspect of the developing spinal cord (initially referred to as the neural tube). In response to interaction between the surface ectoderm and neural plate (which subsequently forms the neural tube), NC undergo epithelial-mesenchymal transformation (EMT), and then migrate (over and through non-NC lineages) and ultimately undergo differentiation along various specific developmental pathways at their sites of colonization[2]. Multiple local signals are thought to regulate the fate and function of these cells as they migrate to their terminal locations[3] (see Table 1). Different regions (loosely based on rostral-caudal neural tube variations) express different molecular expression profiles and can give rise to diverse NC-derived cell types. Due to the wide range of migration and the multistep process of NC morphogenesis in the embryo, they are especially vulnerable to both environmental and genetic disorders. Many congenital birth defects are thought to be due to aberrant NC morphogenesis[4].

\section{CNC SPECIFICATION, EMT, AND MIGRATION TOWARDS THE HEART}

\section{Specification}

Cardiac $\mathrm{NC}(\mathrm{CNC})$, which are a subpopulation of the $\mathrm{NC}$, originate from the lower hindbrain between the otic placode and fourth somite[4,5,6], and undergo EMT and migrate towards the heart via the third, fourth, and sixth pharyngeal arches[7]. They are called CNC because this region of the neural tube provides mesenchymal cells to the heart and the great arteries. The NC-derived mesenchymal cells are often referred to as ectomesenchyme to discriminate them from "normal" mesenchymal cells that are derived from existing mesoderm, suggesting they are intrinsically different $[8,9,10,11,12]$.

Although temporally defined via quail-chick chimeric analysis[13,14,15], chick microsurgical ablation of premigratory neural folds $[4,16]$, and mouse Cre/loxP transgenic lineage mapping data in embryos that have their NC lineages permanently marked with a $\beta$-galactosidase reporter[17,18,19] (see Fig. 1), identification of a CNC-specific inducing factor within the early neural tube has remained elusive. Surprisingly, despite the exquisite anterior-posterior patterning via overlapping homeobox gene expression in the neural tube, relatively few cardiovascular abnormalities have resulted from altered Hox gene expression[20]. To date, there is no CNC-restricted Cre lineage marker mouse line, thus all published lineage mapping data are the result of the simultaneous permanent marking of cranial, cardiac, and trunk NC progenitors. Most commonly used are the P0-Cre, Wnt1-Cre, and Pax3-Cre transgenic lines[17,18,19]. Wnt1-Cre is the earliest NC-restricted Cre line and provides both a useful lineage marker system (Fig. 1) and a means with which to target NC-related genes conditionally.

Although not restricted to the CNC-containing region of the neural tube, mutation of the Pax3 (splotch) transcription factor results in various CNC-related aortic arch and OFT defects[4,19,21]. As this model is $100 \%$ penetrant, it provides a useful genetically defined mouse model in which to study CNC cell morphogenesis. There are five splotch alleles with different mutations of the Pax3 transcription factor: two of these alleles ( $s p$ and $s p^{2 H}$ ) have provided a robust and morphologically well-characterized 

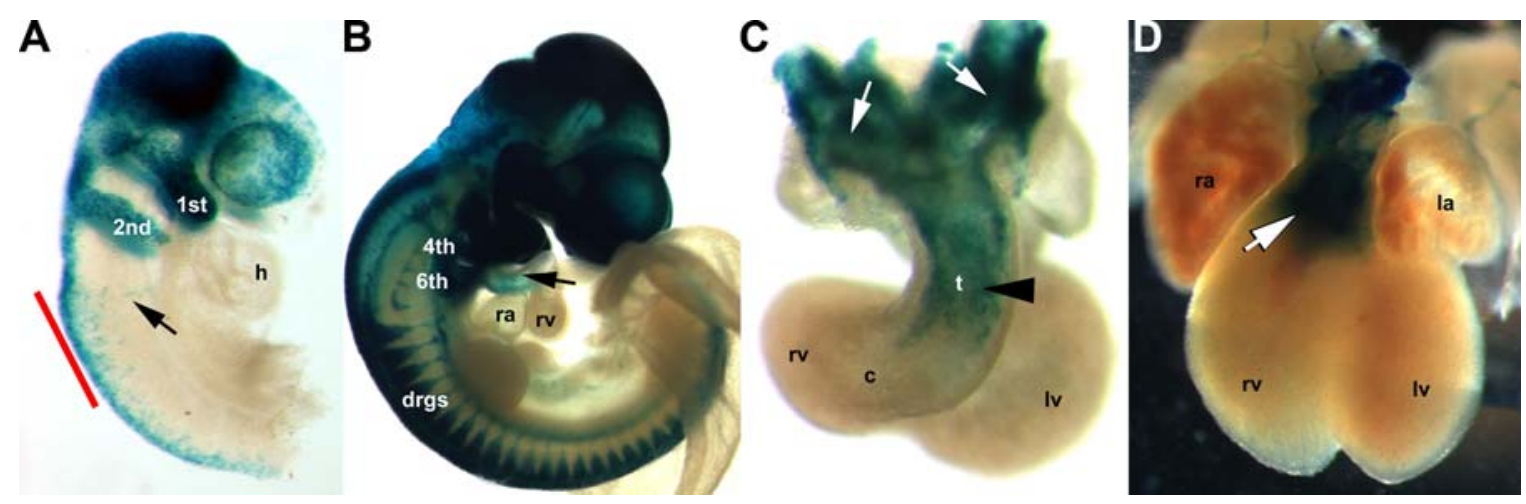

FIGURE 1. Specificity and efficiency of NC marking using the Wnt1-Cre[11] and $R 26 R$ reporter Cre/loxP system. (A) Whole-mount staining of an E8.0 embryo. Labeling is seen in the dorsal neural tube, first and second pharyngeal arches (numbered), and migratory $\mathrm{CNC}$ (arrow). Location of CNC progenitors is indicated by red line. The OFT of the heart (h) is unlabeled, but is in obvious proximity to the pharyngeal arches. (B) Staining in an E11.0 embryo. Extensive labeling is seen in the head, dorsal neural tube, NC-derived dorsal root ganglia (drgs), all the pharyngeal arches (fourth and sixth numbered), and in CNC colonizing the OFT of the heart (arrow). (C) Isolated E11.0 heart. $L c Z$ labeling can be seen in the aortic arch arteries (white arrows) and the truncus (t) of the OFT cushions (large arrowhead), but not in the conus (c). (D) E14 mature septated heart. Note robust lacZ reporter staining is present in the condensed mesenchyme of the OFT conus (arrow) and the anterior divided truncus, but is absent from the ventricles and atria. Abbreviations: rv, right ventricle; lv, left ventricle; ra, right atria; la, left atria.

model of aortic arch and OFT defects[21,22,23,24]. The $s p^{2 H}$ homozygotes[25,26] die in utero and exhibit conotruncal septation defects: persistent truncus arteriosus (PTA) with obligatory perimembranous interventricular septal defect (VSD). The pathogenesis of the defect is due to the failure of the left sixth arch artery to persist, which usually gives rise to the pulmonary trunk (see Fig. 2). In addition, $s p^{2 H}$ embryos exhibit defects within neural tube closure (spina bifida and excencephaly), melanocytes, and lack of limb musculature[27,28]. Significantly, Pax3 mRNA is expressed within the neural tube, migratory NC cells and their derivatives (such as the thymus, thyroid, and dorsal root ganglia), somites, and melanocytes[29]; all structures are abnormal in $s p^{2 H}$ homozygotes. In humans, haploin-sufficient $P A X 3$ mutations lead to Waardenburg syndrome, an autosomal-dominant disorder that consists of defects in NC-derived tissues and is characterized by pigmentation, hearing, and facioskeletal anomalies[30]. Cardiac defects have also been reported in some Waardenburg children[31,32].

Using the $s p^{2 H}$ allele ( $P$ ax3 homeodomain deleted), we have shown that expression of the NC marker $A p 2 \alpha$ revealed extensive reduction in $s p^{2 H}$ migratory CNC lineage. However, the rates of cell proliferation and apoptosis were unaffected and thus do not account for the observed $s p^{2 H} \mathrm{CNC}$-associated heart defects[21]. Significantly, expression analysis revealed $W n t 1$, but not Wnt $3 a$, is expressed at decreased levels within $s p^{2 H}$ and the CNC fail to undergo normal $\mathrm{NC}$ progenitor proliferative expansion prior to migration while still in the neural folds. These data suggest the $s p^{2 H}$ defect is intrinsic to the NC progenitors themselves and there is a decrease in the number of premigratory $\mathrm{CNC}$ that form. It appears this decrease in NC numbers is the primary defect that ultimately leads to a lack of a CNC-derived $s p^{2 H}$ OFT septum. Both the Wnt 1 and Wnt $3 a$ cystein-rich secreted signaling molecules are expressed by NC precursors around the time of neural fold closure[33] and are thought to be essential for initial expansion of $\mathrm{NC}$ in the neural tube[34,35]. Double homozygous null Wnt $/ / W n t 3 a$ mutant embryos have a significant reduction within NC-derived structures that do not seem to result from abnormalities within NC 


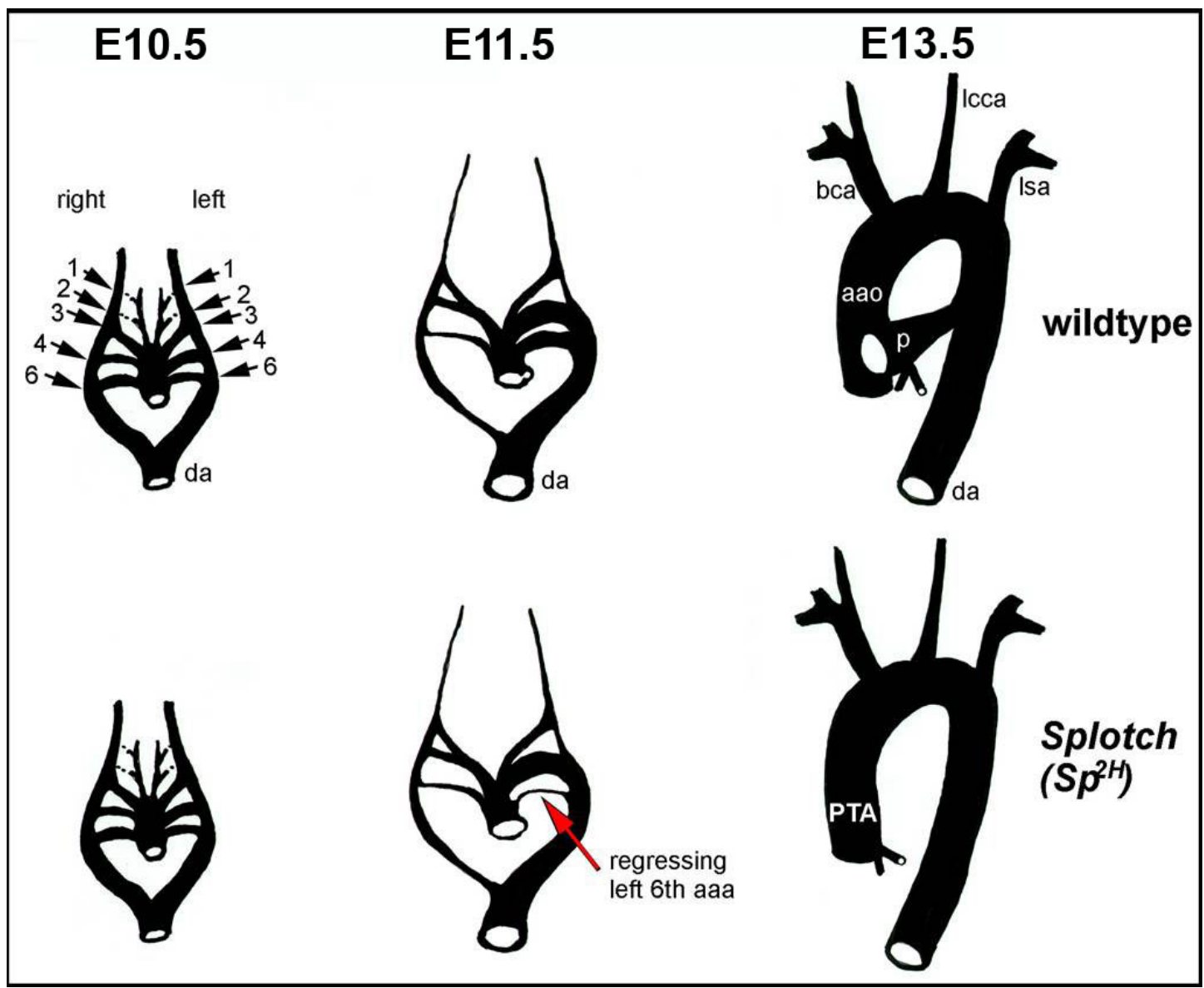

FIGURE 2. Schematic representation of the sequential changes that occur during remodeling of aortic (pharyngeal) arch arteries. Following ink injection analysis[58] of both age-matched wild-type and $s p^{2 H}$ mutant littermate embryos, representative vascular casts were schematized. Upper panel indicates the normal pattern of regression and lower panel indicate the anomalous remodeling occurring within the $s p^{2 H}$ mutant mouse. Normal remodeling. Note that there are initially six symmetrical arteries attached to the paired dorsal aorta (da) that are remodeled to give rise to a separate ascending aorta (aao; partly derived from the left fourth artery) and pulmonary trunk (p; derived from the left sixth artery) with two pulmonary arteries attached. Elements of the brachiocephalic artery (bca) are derived from the right fourth/sixth arteries, the left common carotid artery (lcca) is derived from the left third artery, and the left subclavian (lsa) is derived from the seventh intersegmental artery. $S p^{2 H}$ remodeling. Note there are initially six symmetrical arteries, but that the left sixth (which normally gives rise to the pulmonary trunk) abnormally regresses, resulting in only a single OFT vessel and PTA.

emigration, migration, survival, or differentiation, but rather a lack of NC expansion in the neural tube[34]. Significantly, the $s p$ cardiac phenotype can be rescued by transgenic overexpression of Pax3 under the control of a 1.6-kb neural tube and early NC-specific Pax3 promoter that is not expressed within somites[36]. Transgenically rescued $s p$ homozygotes survive until birth, at which time they succumb to respiratory failure secondary to absence of a muscular diaphragm. Pax3-deficient somites are capable of supporting proper $\mathrm{CNC}$ migration and function, indicating a cell autonomous role for Pax3 during NC morphogenesis. The critical role of $\operatorname{Pax} 3$ in NC progenitor expansion is supported by data that $s p$ homozygote heart defects can also be genetically "rescued" by crossing the $s p$ mutants with the viable Msx2 homeobox-containing null mice[37]. Double Pax3-Msx2 survive until birth and then die due to respiratory failure. These transgenic rescue experiments elegantly demonstrate that $\operatorname{Pax} 3$ is required for the repression of $M s \times 2$ expression within the dorsal neural tube, and that appropriate specification of CNC progenitors is a critical first step. Given that $M s x 2$ is a well-documented regulator of Bmp signaling, it will be interesting to determine what role the TGF $\beta$ superfamily plays during CNC specification. 


\section{EMT}

Although little is known about CNC specification, even less is known about CNC-specific EMT, although the zinc finger genes, Slug, Snail, Id2, and Pinch-1, seem to be involved in specifying EMT competence[5,38,39,40,41]. The details, especially the temporal order of events in NC EMT, vary between different species and between different axial levels, but several important features have emerged[38]. EMT is strongly associated with a decrease in cell-cell adhesion, particularly with loss of $\mathrm{N}$-cadherin on the surface of NC cells at the time of onset of emigration[42]. Similarly, N-Cam adhesion molecule also declines on NC cells. The surrounding extracellular matrix is also important, as EMTrelated changes have been found in several matrix receptors (i.e., integrins), while the nature of the matrix itself is also modified. Changes in Rho family GTP-binding proteins (RhoB), cell shape, and in cell motility also occur at the time of EMT, consistent with changes in the cytoskeleton[43], and these concerted changes can be triggered by TGF $\beta$ superfamily growth factors. Given the exciting identification of $\operatorname{Sox} 9$ transcription factor as a master regulator of trunk $\mathrm{NC}$ induction, survival, and delamination, and the role of the winged-helix transcription factor FoxD3 as a regulator of cell-cell adhesion molecules required for subsequent trunk NC migration[44], it will be interesting to see if a similar mechanism can be identified for the CNC lineage.

\section{Migration}

CNC migration and homing to the third, fourth, and sixth pharyngeal arches and cardiac OFT niches occurs during a well-defined developmental time window and along characteristic circumpharyngeal migration pathways $[15,16,19,45]$. Adhesion molecules, such as integrins, are involved in the interaction of CNC with the extracellular matrix, while cadherins and gap junctions allow CNC to interact with each other during their migration. Migration of $\mathrm{CNC}$ to the heart has been shown to be modulated by interactions mediated by connexin43 $(C x 43 \alpha 1)$ gap junction membrane channels between cells. CNC express $\mathrm{Cx} 43 \alpha 1$, are functionally-coupled[46], and $C x 43 \alpha 1$ knockout mice die at birth with conotruncal heart malformations, outflow obstructions, and coronary anomalies[47,48]. CNC motility is dependent on the level of $\mathrm{Cx} 43 \alpha 1$ function, as loss of $\mathrm{Cx} 43 a 1$ inhibits $\mathrm{NC}$ cell migration, while overexpression enhances migration. Recent chick and mouse studies suggest that $\mathrm{Cx} 43 \alpha 1$ may modulate cell motility, via mediating cross-talk with cell signaling pathways (vinculin and other actin-binding proteins) that regulate polarized cell movement essential for the directional migration of $\mathrm{CNC}$ [49]. In parallel, gap junction formation has been shown to be dependent on cadherin-mediated cell-cell adhesion[50] and a NCrestricted knockout of $\mathrm{N}$-cadherin has recently been shown to result in CNC-related mouse embryonic OFT defects[51]. Significantly, using $N$-cadherin null mouse NC cells, it has been demonstrated that $N$ cadherin can modulate NC cell motility by engaging in dynamic cross-talk with the cells' locomotory apparatus via p120 catenin signaling[50]. In Xenopus, the canonical ( $\beta$-catenin dependant) Wnt signaling pathway is thought to be important for $\mathrm{NC}$ cell induction, while the noncanonical (planer cell polarity) signaling is thought to regulate $\mathrm{NC}$ migration[52]. Using time-lapse analysis on cultured NC cells (either control or cells injected with the dominant negative form of Wnt11 mRNA), it was shown that the noncanonical pathway controls migration by directing the stabilization of cell protrusions necessary for locomotion. When the Wnt noncanonical pathway is disrupted, more CNC cells have filopadia protrusions, but they are significantly less polarized. Thus, Wnt11 is thought to be the activating ligand of the Wnt noncanonical pathway and is expressed adjacent to the CNC prior to migration. This link is further strengthened as it was also shown that the Wnt11 receptor (Frizzled) is expressed in a subpopulation of both premigratory and migratory Xenopus NC cells[52]. 


\section{AORTIC ARCH ARTERY REMODELING DEFECTS ASSOCIATED WITH LACK OF NC}

\section{Aortic Arch Artery Remodeling}

During normal cardiovascular development, the early OFT is a single vessel that branches at the aortic sac into the bilaterally symmetric third, fourth, and sixth aortic arch arteries present within the pharyngeal arches. Remodeling of these transient symmetrical arch arteries into the definitive adult left-sided aortic arch vascular pattern involves the asymmetrically programmed regression and persistence of specific arch arteries (see Fig. 2). The third arch arteries give rise to common carotid arteries, fourth arch arteries contribute to the formation of the distal part of the aortic arch, the brachiocephalic artery and a proximal part of the right subclavian artery, while the sixth arch arteries contribute to the ductus arteriosus and the proximal parts of the pulmonary arteries. The final arrangement and morphology of these great vessels requires reciprocal signaling between the endothelial cells lining the pharyngeal arch arteries[53], the surrounding NC-derived smooth muscle and mesenchyme[54,55], and the endoderm[56,57]. Anomalous remodeling underlies a wide variety of congenital heart defects including: PTA, coarctation and interruption of the aortic arch, double aortic arch, right aortic arch, and abnormal origin of the right subclavian (pathogenesis of these defects reviewed in Conway et al.[58]). PTA arises when the arterial trunk fails to be divided to form a separate pulmonary artery and aorta. Despite the presence of many different mouse mutant models of anomalous aortic arch artery development (several within the DiGeorge region), the precise role of the $\mathrm{CNC}$ during aortic arch artery morphogenesis is not well understood[7,22,59].

\section{Colonization of Pharyngeal Arches}

The pharyngeal arches are initially composed of mesenchyme (mesodermally derived), which is surrounded externally by ectoderm and internally by endoderm. Subsequent to CNC colonization, most of the mesenchyme is CNC derived, apart from the original mesodermal core that lies adjacent to the aortic arch arteries[18]. In addition to a variety of complex gene expression profiles[6], the mesenchyme of both the anterior and posterior pharyngeal arches contain different partially restricted intermediate cell types derived from the $\mathrm{NC}[60]$, suggesting that the pharyngeal arches are segmentally patterned. CNC-derived mesenchyme subsequently condense and differentiate into fibrous connective tissue that contributes to vascular stabilization of the great arteries[7], while other NC populate the cardiac ganglia[15]. A substantial population of CNC-derived cells in the pharyngeal arches remains associated with the pharyngeal arch arteries, and constitutes the smooth muscle layer that surrounds these vessels as they become reorganized into the arch of the aorta, the ductus arteriosus, and the proximal segments of the carotid arteries[18,61]. Comparison of chick and mouse CNC migration patterns using a combined Cx43lac $Z$ mouse transgenic marker and quail-chick chimeras clearly demonstrated that CNC migration is similar within the pharyngeal region[15]. The similarities include the formation of a sheath around the aortic arch arteries and population of the cardiac ganglia. However, it is still unclear what role the CNC play during asymmetric remodeling and whether they play an instructive role or secondarily respond to other stimuli (for instance differential blood flow patterns and/or neural innervation). Migration of a subpopulation of CNC continues on into the cardiac OFT where they populate the conotruncal cushions[4,23,24] and, by currently unknown mechanisms, they participate in OFT septation[62]. NC from this same region of the mouse neural tube also give rise to cells of the thymus, thyroid, and parathyroid glands[18,19]. There is extensive experimental evidence (little of which is genetic) suggesting that the various steps in NC morphogenesis and cell fate are influenced by cell-cell and cell-matrix adhesions[63,64] and the environment through which they migrate[3]. Consequently, the pharynx is a likely source of important instructive signals for the migrating CNC. In fact, the primary fate of the CNC lineage is to differentiate into the smooth muscle of the aortic arch arteries and cardiac OFT[1,18,61], and 
require NC autonomous expression of Pdgf receptor $\alpha[65]$, Alk2 receptor[66], and Alk5 receptor expression[67].

Although our understanding of the role of the $\mathrm{CNC}$ remains mostly descriptive, some insights into the cellular processes have come from experimental manipulation of chick embryos[4,11] and the genetic processes from mouse, zebrafish, and Xenopus mutants[68]. In chick embryos, neural fold/NC ablation[4], Hox antisense experiments[20], teratogenic retinoic acid exposure[69], and hemodynamic perturbations[70] have all caused fourth and sixth pharyngeal arch abnormalities. Similarly in mouse, teratogenic exposure to haloacetic acids[71], ethanol[72], and retinoic acid gives rise to arch abnormalities. Related or analogous pathological defects of the mouse fourth and sixth pharyngeal arches and OFT are also seen when a large number of genes have been transgenically altered[73,74]. For instance, the $s p^{2 H}$ homozygotes[23,24,25,26] die in utero and exhibit PTA with obligatory perimembranous VSD due to the failure of the left sixth arch artery (which would normally form the main pulmonary artery segment) to persist. Using ink injection casts to assess third, fourth, and sixth pharyngeal arch artery remodeling, we found that all three pairs of arch arteries were formed, but that both the left and right sixth arch arteries underwent vascularization and disappear in $s p^{2 H}$ homozygotes when compared to wild-type littermates (see Fig. 2). This suggests that pulmonary atresia underlies the OFT defects and that only one vessel remains that exits the heart. We have also shown that presumptive $s p^{2 H}$ homozygote $\mathrm{CNC}$ stem cells fail to undergo normal progenitor expansion within the neural tube and consequently insufficient CNC colonize the pharyngeal arches and OFT[21]. This suggests that normal aortic arch artery remodeling is partly dependent on a particular threshold number requirement of colonizing NC. Similarly, when any of the aforementioned manipulations result in elevated CNC apoptosis and/or suppressed NC proliferation, anomalous remodeling of the aortic arch arteries and/or vascular regression is often a downstream consequence[73,74].

\section{Coordinated CNC-Derived Mesenchyme Differentiation is Required for Remodeling of the Arterial Tree}

Mutational analysis has identified a large number of genes required for morphogenetic and inductive processes involving the mouse $\mathrm{CNC}[4,22,68]$. These genes appear to involve several different pathways acting in parallel or in series with one another, but there is currently no simple pathway that unifies all the available data. Some genes, including $\operatorname{Pax} 3$ and $A p 2 \alpha$, are expressed in the migrating $\mathrm{CNC}$ as they relocate to their positions around the great vessels and OFT[21,23]. More recent evidence suggests that these interactions, and the programming of the $\mathrm{CNC}$, are mediated by transcription factors including Foxc1/Foxc2, Hand1/Hand2, and Tbx1 and other genes on human chromosome 22q11[68,75,76,77]. Another set of genes is expressed within the developing vasculature itself, and may play a role in vessel formation, stabilization, and remodeling (Vegf-A[78]; neuropilin-1[79], or within the interacting mesenchymal cells (Mef2c[80]; Tissue factor [81]). This has led to the idea that the control over vascular assembly resides within the connective tissue-forming NC-derived mesenchyme. In support of these reciprocal interactions, Noden[82] found similar results using quail-chick transplantation. Finally, there is still another set of genes that is expressed in the pharyngeal arches themselves, and may play a role in mediating interactions between the arch epithelia (ectoderm and endoderm), mesenchyme, and endothelial vessels (Endothelin-1[83]; Ece-1[53]; EtA[84]; Semaphorin3c[85]). Interestingly, TBX1, a gene associated with DiGeorge syndrome, is not expressed in the $\mathrm{CNC}$, but in the adjacent mesendoderm of the pharyngeal arches[86]. Furthermore, expression of the secreted growth factor $F g f 8$ is diminished in $T b x 1$-expressing cells from Tbxl mutant mice[57], and mice deficient in $\mathrm{Fg} 8$ exhibit elevated levels of CNC cell apoptosis and the typical DiGeorge syndrome interrupted aortic arch phenotype[87,88]. However, it is not currently known whether CNC cells are direct targets of Fgf8 or whether its effect is indirect. Although down-regulation of Bmp signaling in pharyngeal endoderm seems to be a prerequisite for CNC cell survival[86,89,90], NC-restricted deletion of Bmp type I receptor Alk2[61] results in abnormal maturation of the aortic arch arteries and PTA. Thus, it is possible that Fgf and TGF $\beta$ 
superfamily signaling pathways converge to control CNC cell fate during both aortic arch artery remodeling and cardiac OFT morphogenesis[67].

Cell fate studies using a transgenic Cre/lox $P$ cell marking technique have demonstrated that the mere presence or absence of $\mathrm{CNC}$ is not sufficient to cause remodeling, as there do not appear to be any differences in the distribution between those arteries that persist vs. those that regress[18]. This suggests that different left-right signals required for remodeling must be carried by the colonizing $\mathrm{CNC}$ or are present within the mesodermal core, endothelial cells lining the arch arteries, or within the pharyngeal pouch/cleft endoderm. The origin and identity of these signal/s is currently unknown, but may involve retinoic acid levels[91] or differential activity of ion channels (Polycystin-2[92]) giving rise to unidirectional transfer through gap junctions, resulting in asymmetric gene expression[93]. Currently, Pitx2 [94] is the only known gene asymmetrically expressed within the pharyngeal arch mesoderm, and it has been shown that an isoform-specific deletion of Pitx2c results in abnormal patterning of the aortic arch vessels[94]. Thus, it is well established that $\mathrm{CNC}$ can provide structural integrity and may also carry instructive signals required for aortic arch remodeling. Disruption of this signaling leads to defects in the interactions between postmigratory $\mathrm{CNC}$ and the endothelium of the great vessels and OFT. Collectively, these results support a model in which epithelia/endothelia of the arches signals to NC-derived mesenchyme (possibly via processed Et-1, Semaphorin, and/or Vegf) possibly through gap junctions. However, it is unclear exactly what the function of the NC is within the arches and OFT, how they differentiate into connective tissue, and which genes respond to the various CNC-mediated differentiation signals.

\section{ROLE OF CNC IN OFT DEVELOPMENT}

\section{OFT Elongation and Septation}

A subpopulation of the CNC continues migration and colonizes the common OFT endocardial cushions. Although the CNC cell patterns in the pharyngeal region are similar in mouse and chick embryos, a couple of notable differences have been reported as they enter the OFT cushions prior to septation[15]. In quail-chick chimeras, the CNC enter by two distinct routes, subendocardially and submyocardially. This contrasts with the single subendocardial entry route of $C x 43-l a c Z$ marked mouse CNC. Furthermore, migration of CNC cells into the mouse OFT extends all the way to the distal conus, whereas they only extended into the conus in the chick and do not reach the conotruncal transition. These CNC patterning differences between species may be due to innate morphological differences between mammals and birds, as well as differences in timing of some of the developmental events in cardiovascular development[15]. Elongation of the OFT is a prerequisite for correct looping, complete rotation, and appropriate alignment during OFT septation. Both the CNC and anterior heart field (AHF) lineages are required for OFT elongation, as the CNC contribute to the existing conal endocardially derived OFT mesenchymal cushions, while the AHF cells contribute to the OFT myocardial cuff and most of the right ventricle[95]. Following CNC cell colonization of the truncal cushions, the common OFT is divided into a separate pulmonary artery and the aorta. This is accomplished by the development of the endocardial cushion conotruncal ridges, which grow caudally in a spiral fashion, resulting in posteriolateral realignment of a separate aorta and anteriomedial realignment of a separate pulmonary artery. This spiral septum fuses with the bulbar ridges, which, together with proliferation of the inferior endocardial cushion, close the interventricular septum (failure to do so results in VSD). Chick studies have shown that labeled CNC cells can undergo apoptosis on completion of septation[11,96], however, there are limited data as to whether this also occurs (and to what extent) during mammalian OFT septation. Martinsen et al. discussed the observation that there is an extension of the CNC to the rim of the right ventricular outflow tract[98] and that the ultimate fate of these deep CNC cells may be apoptosis[97,98,99]. This would explain why there are no NC-derived septal structures below semilunar valve level[97,99]. Furthermore, it is hypothesized that as the NC under go apoptosis, they may release or mobilize growth factors[97]. The 
population of deep migrating cardiac $\mathrm{NC}$, whose fate is cell death, may be marked by $I d 2$, which also marks the secondary heart field and ganglia of the anterior parasympathetic plexus[98]. Similarly, mouse CNC cells in the OFT colocalize in a knot of TUNEL-positive condensed mesenchyme that transiently express a Wnt receptor Frizzled-2[100], suggesting a role in remodeling and patterning during septation. However, using transgenic mouse Cre/loxP cell marking techniques, it has been shown that CNC cells populate the conotruncal cushions and contribute to cardiac tissue found at later stages of fetal heart development and to a lesser extent in the adult heart[17,18,19]. Thus, not all the mouse CNC cells undergo apoptosis and a distinct population can be found in the mature heart. Initially, Wnt1-Cre permanently labeled mesenchymal cells project from the aortic sac in an unbroken stream through the conotruncal region, up to the junction of the conus with the wall of the right ventricle[18]. However, during septation and fusion of the spiral septum, the widely distributed $\mathrm{CNC}$ become localized within a thin subendothelial layer along the seam of fusion. Thus, it appears that the mass of CNC-derived cells that constitutes the early aorticopulmonary and conotruncal mesenchyme mostly dies or is overgrown as septal formation is completed[18].

\section{Remodeling of the OFT Septum}

Once in the OFT cushions, it has been suggested the CNC cells are involved in fusion and subsequent myocardialization of the proximal OFT, giving rise to the muscular outlet septum of the heart[101]. Rather than transformation of endocardial cushion cells (either endothelial or NC derived), it is thought that normal myocardialization of the cushions is caused by a redistribution of existing cardiomyocytes and regulated by (as yet unknown) secreted factors[102]. Myocardialization is only seen to occur in cushion mesenchyme, which is found inside the heart tube, and never in the epicardial mesenchyme, which covers the heart at the outside. Thus, the observation that disruption of one of the noncanonical Wnt pathway core planer polarity molecules leads to OFT misalignment defects is exciting[103,104], as this suggests cytoskeletal changes that affect cell adhesion, motility, and polarity do play a role during OFT septation. Similarly, NC-restricted N-cadherin deletion results in OFT remodeling defects and PTA[105]. The Ncadherin null OFT cushions exhibit misshapen (more rounded) CNC cells with fewer cell-cell contacts when compared with wild-type littermates, and undergo elevated levels of apoptosis, indicating that $\mathrm{N}$ cadherin is required for CNC cell survival in the OFT. However, the precise role of the CNC cells and the molecular mechanisms responsible for the normal remodeling of the initial common OFT into two asymmetrical OFT vessels is largely unknown. For instance, it is unclear exactly how CNC differentiate into connective tissue and what CNC-mediated differentiation signals are expressed during septation. Finally, although there are several markers expressed during CNC cell migration into the arches and up to the OFT[21,23], there are currently no markers/candidates that are expressed in the CNC cells as they enter, undergo differentiation, and/or reside within it. This makes the elucidation of their role and function once they reach the heart elusive. This is a particular drawback when considering the ultimate role of the OFT mesenchymal cushion cells in OFT morphogenesis and pathogenesis of congenital heart defects. Thus, it is critical to find new genetic targets that either continue to be expressed as the CNC cells colonize the heart or get turned on by the colonizing CNC cells in the OFT. The field needs a broader array of molecular markers to help dissect both the earlier and later steps of CNC cell colonization of OFT[6], as well as a better understanding of the signals seen by the CNC cells that are involved in aortic arch artery remodeling and formation of OFT septum.

\section{Unexpected Roles of NC}

Given that the vast majority of CNC molecular markers, both mRNA and protein, are switched off as CNC colonize the OFT cushions and our reliance is on only a couple of transgenic marking techniques, the ultimate fate of the $\mathrm{CNC}$ remains uncertain. While most studies have supported the role of $\mathrm{CNC}$ in 
OFT septation, several mouse and chick lineage marking experiments have also suggested a wider unexpected role for the $\mathrm{CNC}$ deep within the heart. Using retroviral labeling of the neural tube prior to EMT, it has been shown that CNC cells can enter the embryonic chick heart from two areas. First is the well-known pathway through the pharyngeal arches and into the arterial pole. The second entry is via the venous pole and dorsal mesocardium[106]. The arrival of $\mathrm{NC}$ to the venous pole occurs later in development than those in the OFT, and they can migrate to the atrioventricular cushions and surround the conduction system. Once venous pole cells reach these destinations, they appear to undergo apoptosis coincident with physiological function changes in the conduction system. Complimentary Cre/loxP mouse lineage mapping studies using Wnt1-Cre have similarly reported that NC cells can enter the heart from both venous and arterial poles[107]. The colonizing arterial pole CNC are associated with the cardiac conduction system and can contribute to bundle branches, while the venous pole cells contribute to the sinoatrial and atrioventricular nodes[107]. Using the same Wnt1-Cre (in parallel with complimentary $\mathrm{P} 0$-Cre mice), in conjunction with both the $\beta$-galactosidase and EGFP Cre/loxP lineage mapping system, a recent report demonstrated that a significant number of $\mathrm{NC}$ was seen to contribute to the adult semilunar and atrioventricular valves[108]. These studies also showed that NC enter from both the venous and arterial poles and can contribute to the proximal conduction system at late developmental stages. Furthermore, the NC in the atrioventricular valves simultaneously expressed several NC-related differentiation markers, suggesting some $\mathrm{NC}$ in the embryonic heart are not fully differentiated and may remain multipotent[108]. Two possible reasons for these apparent discrepancies with previous reports[11] and our own lineage mapping data (Fig. 1) are thought to be mixed vs. inbred genetic background effects that might allow CNC to migrate further than has previously been seen by others, and/or differences in Cre expression levels and types of indicator mice used (i.e., ROSA26R vs. CAGCAT-EGFP mice). Using the NC-restricted $\mathrm{PO}$-Cre lineage marker mice crossed to floxed EGFP indicator line, one group has intriguingly shown that a small population of EGFP positive NC in the heart can colocalize with known stem cell markers[109]. Retroviral labeling of the chick neural tube was also used by Sohal et al.[110], who found that neuroepithelial cells may emigrate from the ventral side of the neural tube (termed VENT cells) and can give rise to numerous cell types in the developing cardiovascular system. Based on celllabeling studies in the hindbrain of avian embryos using replication-deficient retroviral vectors containing $L a c Z$ to permanently label their progeny, VENT cell emigration is thought to occur after CNC emigration has ceased[110]. However, the colonization of the heart was inferred retrospectively after examining numerous embryos harvested at different stages. Given these shortcomings and the lack of any specific molecular marker, it is unclear whether there is a contribution of ventral neural tube cells to the heart[111,112].

Surprisingly, identification of these various unexpected roles of NC have all used many of the same techniques and reagents that were initially employed to define the traditional role of the CNC lineage during OFT septation. Although each of these studies is in agreement as to the fact that the majority of the CNC colonize the pharyngeal arches and OFT, the fact that they do all report a lesser (but detectable) contribution to the heart is significant. Our own studies with the Wnt1-Cre $x$ R26R reporter system match those reported by Jiang et al.[18] and have thus far failed to detect venous pole entry or labeled CNC in the valves (unpublished). Intriguingly, Kirby and colleagues have shown that double ablation of the nodose placode and the CNC yields more consistently PTA[113]. Thus, nodose placode cells could be a population of cells that compensates for the CNC that are not always present in the unexpected lineages[113].This suggests that the degree to which these unexpected derivatives are detectable may depend on the various genetic backgrounds of the mice lines, as it is unlikely that variable Cre-mediated recombination efficiencies could account for these consistent differences. Although these data are difficult to reconcile with many of the traditional CNC-related phenotypes seen with various experimental and/or genetic NC targeting studies, the known pluripotent nature of NC means that unexpected derivatives warrant further investigation. Collectively, these intriguing results suggest that, depending on the setting of experimental and/or genetic CNC abnormalities present, and the genetic background used, $\mathrm{NC}$ can make their way into the rest of the heart, but they do not necessarily do so. Given that these 
derivatives do not always contribute to these unexpected lineages and are not always present, it remains to be seen what role they play when present.

\section{CNC CELL EFFECTS ON MYOCARDIAL DEVELOPMENT}

\section{Pax3 Mouse Model}

In embryos homozygous for two different splotch alleles ( $s p$ and $s p^{2 H}$ ) that each contain Pax3 mutations, all the mutants exhibit PTA (with obligatory VSDs) and die mid-gestation. The presence alone of PTA/VSD should not cause in utero lethality[58], as the systemic and pulmonary circulations are not required to be separate until birth, thus additional causes of lethality have been investigated. Significantly, $100 \%$ of the $s p^{2 H}$ homozygous mutant embryos die $\sim$ E14.0 and exhibit edema, pooling of blood in caval veins, and engorgement of the fetal liver, which are all suggestive of poor cardiac function[23,24]. Deficiencies in myocardial $\mathrm{Ca}^{2+}$ handling further compromise cardiac function, as there is abnormal excitation-contraction coupling in the $s p^{2 H}$ mutant cardiomyocytes[24]. It has been proposed that this myocardial defect is an indirect consequence of the reduced numbers of migrating $\mathrm{CNC}$ [37] because they are not generally thought to contribute to the myocardium[18]. The $s p$ homozygous embryos also die $\sim$ E14.0 due to cardiac failure, but the $s p$ hearts also present with a thinned myocardium and an absent compact zone[36] (see Fig. 3). Using subtractive hybridization to identify mRNA transcripts whose expression is enhanced between E10.5-13.5 in normal hearts, it has been shown that p57Kip2 (which encodes a cyclin-dependent kinase inhibitor of the $p 21$ family) is up-regulated and ectopically expressed in the myocardium of $s p$ embryos[114]. As the $s p$ cardiac OFT and thinned myocardial phenotype can be rescued by transgenic overexpression of neural tube/NC-restricted Pax3[36], this suggests that the $s p$ myocardial defects are CNC-related. Similarly, Pax3-FKHR knockin heterozygous mice are not viable and $100 \%$ die $\sim$ birth due to presence of VSD and exhibit cardiac insufficiency, and a grossly enlarged septum with a dilated OFT[115]. It is currently unclear if the Pax3-FKHR knockin is acting as a "dominant-negative" mutation affecting the heart (as Pax3 itself has not been thought to play a role in myocardial morphogenesis) or if the Pax3 mutation directly affects the heart (as Pax3 protein is detectable within isolated valvular cells in the E16.5 heart). Although not identical, it is interesting to note that both the Pax3-FKHR and $s p^{2 H}$ mutants lack the C-terminal portion of the homeodomain that modulates DNA binding activity and controls specificity of target sequences[116]. As $s p^{2 H}$ hearts have an intact compact layer, but still die in utero, we assessed trabecular and compact layer-restricted gene expression (Fig. 4). In contrast to $s p$ mutants[114], $s p^{2 H}$ mutants express normal levels and patterns of Anf, Bmp10, p57Kip 2 and $N$-myc, suggesting that lack of normal CNC colonization can affect different myocardial maturation signaling pathways that ultimately result in poor cardiac function and lethality.

Although a direct role for Pax3 during cardiomyocyte morphogenesis remains elusive, Schafer et al.[117] have suggested that the Lbxl homeodomain-containing transcription factor and Pax3 are involved in a regulatory feedback loop to repress each other indirectly within the ventricle. A small population of Lbx1 expressing NC migrate from the neural tube into the caudal pharyngeal arches and on into the OFT. Lbxl null embryos have cardiac looping defects, alterations in connexin gene expression, and hyperplasia of the myocardium[117]. $L b x l$ is up-regulated in $s p^{2 H}$ mutant ventricles, suggesting that Lbxl null CNC are not programmed correctly and can disrupt heart development, resulting in cardiac malformations[117]. Complex embryological defects, including CNC and myocardial dysfunction, can be experimentally induced via prenatal exposure to the herbicide nitrofen[118]. Correlating with the aforementioned data, Pax3 mRNA is decreased in rat embryo hearts that exhibit CNC-associated nitrofeninduced defects. As myocardial maturation is known to be regulated by adjacent epicardially derived signals[119,120], and as Pax3 is not thought to be normally expressed by cardiomyocytes[121], these data suggest that a direct contribution by the CNC to the epicardium is an intriguing possibility. Although Wnt1Cre expression has been associated exclusively with the NC and derivatives[18,122], the epicardium of 


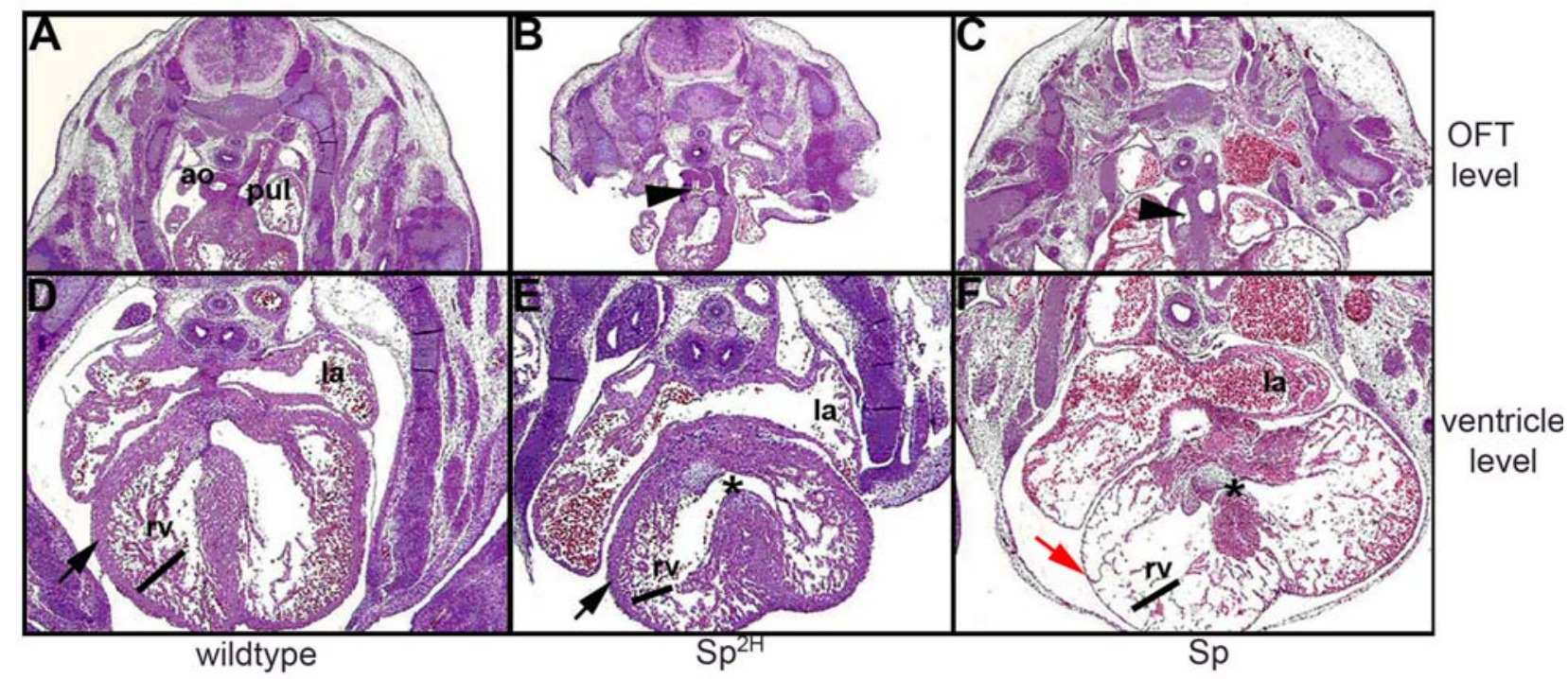

FIGURE 3. Histological analysis of the E13.5 ventricular myocardium in wild-type and pax3 allelic mouse mutants. (A and D) Wild-type, (B and E) $s p^{2 H}$, and (C and F) $s p$ embryonic hearts transversely sectioned. Note that both the $s p^{2 H}$ and $s p$ homozygous mutants have OFT defects (arrowheads) and VSDs (indicated by *), but that only the $s p$ myocardium is abnormally thin. Trabeculation (indicated by bar in right ventricles; rv) is still present in $s p$ mutants (although sparse), but the highly proliferative $s p$ compact layer (indicated by red arrow) is severely diminished when compared to $s p^{2 H}$ and wild-type littermates (arrows in D and E). Abbreviations: ao, aorta; pul, pulmonary artery.
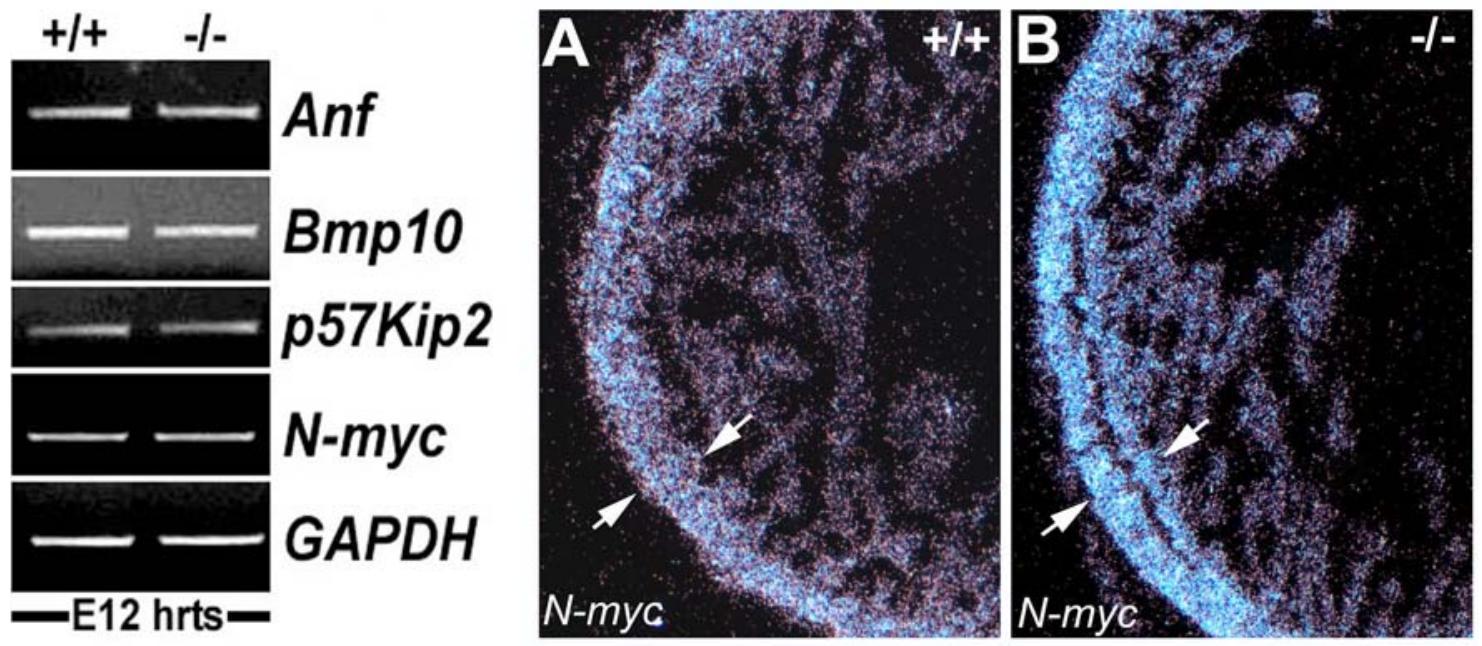

FIGURE 4. Molecular marker analysis of the E12 ventricular myocardium. (Left panel) RT-PCR analysis of trabeculae and compact layer-specific marker expression in wild-type and $s p^{2 H}$ mouse mutant hearts. Expression levels of the trabecular marker genes atrial natriuretic factor (Anf), bone morphogenetic factor 10 (Bmp10), and p57Kip2 are unaffected in homozygous $s p^{2 H}$ hearts when normalized with GAPDH housekeeping gene expression. Similarly, expression of $N$-myc, a marker of compact myocardium, is normally expressed in mutant hearts. (Right panel) Radioactive in situ hybridization analysis of $N$-myc expression patterns supports the RT-PCR data and reveals that the $s p^{2 H}$ compact layer (B) is present and appropriately expresses $N-m y c$ in the proliferative compact myocardial layer (indicated by arrows).

some Wnt1-Cre $x$ R26R embryos has been reported to contain a small population of recombined cells[123] that could interact with the adjacent myocardium. In order to address these unanswered questions, we generated a "tissue-specific" targeted knockout of Pax3, that in conjunction with cardiomyocyte and epicardially restricted $\mathrm{Cre}$ mice, will enable us to begin testing whether the observed poor $s p^{2 H}$ cardiac dysfunction is due to either null primary effects of the Pax3 mutation in the cardiomyocytes or secondarily 
due to earlier $\mathrm{CNC}$ and/or epicardial effects. These lineage-restricted knockout approaches will also enable us to determine whether abnormal CNC morphogenesis is sufficient to give rise to abnormal aortic arch morphogenesis, or whether myocardial dysfunction is additionally required.

\section{Direct or Indirect Effects on Cardiomyocyte Proliferation?}

Similar to the Pax3 mouse mutants studies, Kirby and colleagues have also shown that premigratory CNC ablation in chick consistently results in myocardial dysfunction prior to the arrival of the CNC within the heart, and have suggested that these early effects on the heart are due to a prolonged release of secreted growth factors (FGFs, etc.) by the pharyngeal endoderm, which are normally involved in the induction of cardiac mesoderm[15]. These FGF signals are proposed to suppress chick myocardial development and calcium transients/contraction, and alter myocardial proliferation/differentiation in the absence of $\mathrm{CNC}[15,124]$, but are prevented from disrupting cardiomyocyte morphogenesis when the full complement of CNC are present in the pharyngeal arches and OFT septum. These data suggest that the endocardium can indirectly have deleterious effects on myocardial maturation, as a consequence of absent CNC colonization.

Genetic evidence also indicates that normal CNC morphogenesis is necessary for normal myocardial development and in utero viability. Conditional deletion of Bmp receptorla specifically in the NC using Wnt1-Cre results in defective myocardial formation, as well as a shorter OFT that fails to septate[123]. These mutant embryos die $\sim$ E12 with acute heart failure and exhibit a notable lack of ventricular myocardial proliferation. Lineage-tracing experiments suggested that a small population of permanently marked NC might be able to migrate to the epicardium[123]. Similarly, Wnt1-Cre conditional deletion of $\mathrm{N}$-cadherin results in embryonic lethality $\sim \mathrm{E} 13$ and OFT remodeling defects that resulted in PTA in the majority of the mutants[105]. N-cadherin NC-specific mutants are thought to die due to a thinned ventricular myocardium and detachment of myocardium from adjacent epicardium. Normally, the epicardium expands in an epithelial sheet to cover the ventricular surface, from where epicardial cells invade the underlying myocardium. Given that a few CNC can populate the epicardium[123], the reduction in ventricular wall thickness in both these NC-restricted mutants could be due to either a direct effect on the NC-derived epicardial cells that invade the myocardium (like other epicardial cells); or they could be secondarily due to loss of epicardial-myocardial signaling or Bmp receptorla/ $\mathrm{N}$-cadherin insufficiency in the $\mathrm{CNC}$ and their subsequent inability to effectively colonize the OFT. It has been suggested that perhaps the CNC produce a factor that stimulates myocardial proliferation, and when inappropriately specified, they are unable to respond to OFT-restricted stimuli and consequently myocardial proliferation is reduced[123].

A second cell lineage, the AHF, has also been shown to play a major role during OFT development and septation. The AHF in mouse includes the early pharyngeal core arch mesoderm and splanchnic mesoderm, which overlie the ventral pharyngeal endoderm and can be identified prior to $\mathrm{NC}$ emigration within the primary heart field as early as the cardiac-crescent stage[125,126]. As AHF cells contribute to definitive OFT myocardium as well as to the right ventricle and some endocardium[127,128], inappropriate cardiomyocyte specification of the AHF lineage could subsequently result in compromised myocardial development. Given that the AHF and $\mathrm{CNC}$ may be interdependent, because surgical ablation of either $\mathrm{CNC}[10]$ or AHF[129] results in changes in OFT length, myocardial dysfunction could possibly result from inappropriate CNC-AHF cross-talk. Similarly, recent lineage-specific deletion of the Shh morphogen has elegantly shown that a Shh pharyngeal endodermal signal is directly required by both the AHF and CNC for normal OFT morphogenesis[130]. The possibility of AHF and CNC interactions suggest that communication and dynamic intracellular signaling among multiple lineages may be crucial during $\mathrm{CNC}$ colonization of the pharyngeal aortic arches and OFT development and septation. 


\section{CNC Species-Specific Differences}

In contrast to their mammalian and chick $\mathrm{CNC}$ counterparts, zebrafish $\mathrm{CNC}$ originate more rostrally along the neural tube, and can contribute to the myocardium and may have different functions in a species-dependent context[131]. Given the absence of OFT septation in zebrafish, it was unclear whether there would be any $\mathrm{CNC}$ contribution to the zebrafish heart. However, using three lineage-tracing techniques, it has been demonstrated that they contribute to the pharyngeal arches and OFT, but additionally they were found to incorporate into the myocardium and differentiate into muscle[131]. Given the myocardial contribution, laser ablation of zebrafish CNC more severely affects ventricular function when compared with chick/mouse[132]. It is thought that perhaps birds and mammals have acquired signals that stop the CNC in the OFT, rather than traveling deeper in the heart, so they are in the right location to participate in septation. Evolutionarily, zebrafish heart development occurs without the subsequent modifications that $\mathrm{CNC}$ contribute to in birds and mammals, and the advancement of divided circulation could be the reason CNC switched from a myocardial to mesenchymal phenotype[131]. The $\mathrm{CNC}$ lineage has also been shown to be important for Xenopus heart development[98]. In Xenopus, NC migrate from the neural folds throughout the embryo and give rise to multiple cell types, but rather than the highly restricted closely related sheet of NC observed in mouse/chick embryos, the NC in Xenopus were much fewer, migrated individually, and were less restricted. When premigratory CNC were ablated in Xenopus, expression of a presumptive NC marker (xId2 transcription factor) was reduced in pharyngeal arches and absent in the OFT, inflow tract, and myocardium[98].

\section{CNC STEM CELLS}

At the onset of migration, the NC represent a heterogeneous population of cells with regard to their developmental potentials. It has been suggested that they consist of a mixture of stem cells, fate-restricted cells, and cells that are committed to the smooth muscle cell lineage[133]. The existence of pluripotent progenitors was shown by in vitro clonal analysis[134,135] and by labeling individual NC cells in vivo[136]. Both approaches demonstrated that an individual cell can give rise to an array of differentiated progeny, including sympathetic neurons, sensory neurons, Schwann cells, melanocytes, smooth muscle cells, chondrocytes, fibroblasts, and possibly other cell types[137].

Two recent mouse Cre/loxP NC lineage mapping studies have similarly suggested some CNC exist in the embryonic heart that are not fully differentiated and may be multipotent $[108,109]$. Using the NCrestricted $\mathrm{PO}$-Cre lineage marker mice crossed to floxed EGFP indicator line, it was shown that a small population of EGFP positive CNC in the heart colocalize with known stem cell markers[108]. Multilineage progenitor (side populations) cells in the heart were identified by cell surface marker expression, nestin, size, proliferation, ability to form spheres in culture with no serum, and the ability to lose multipotency following addition of serum. These P0-Cre marked cells could be expanded in culture and differentiated into cardiomyocytes, smooth muscle cells, neurons, and glia[109]. A second group also used the P0-Cre (and Wnt1-Cre) lineage marker mice, but this time crossed them to the R26R lacZ indicator line and found that a significant number of $\mathrm{NC}$ was seen to contribute to the adult semilunar and atrioventricular valves. Marked CNC were observed to enter the atrioventricular valves from both the venous and arterial poles, and were shown to contribute to the proximal conduction system at late developmental stages[108]. Intriguingly, lineage-specific antibody immunohistochemistry indicated that some NC-derived cells in the atrioventricular valves expressed melanocyte and neurogenic markers, some $\mathrm{NC}$-derived in the cardiac conduction system expressed neurogenic and gliagenic markers, and another population of NC-derived cells expressed no differentiation specific markers at all[108]. Thus, it has been suggested that multipotent/stem cells with $\mathrm{NC}$ origin exist dormant in the neonatal heart and, on receiving the right signals, could differentiate into various cell types, thereby offering therapeutic potential. 


\section{CONCLUSIONS}

The critical requirement of the $\mathrm{CNC}$ during cardiovascular development is well documented, as are the severe and diverse congenital consequences associated with their removal and/or genetic manipulation (see Table 1). Both animal models and human candidate gene-mapping approaches reveal that multiple interacting signaling pathways play a role during CNC formation, migration (schematized in Fig. 5), and colonization of the heart. Local cell-cell interactions among the endothelium, AHF, pharyngeal endoderm and ectoderm, and cardiomyocytes appear critical during subsequent colonization and septation of the OFT. The challenge now lies in integrating these data and identifying the common underlying mechanisms and relationships between these implicated signaling pathways. Systemic and conditional gene deletion and lineage mapping studies have proved tremendously effective, and enabled us to build a mechanistic framework that explains some of the molecular mechanisms controlling the coupled abnormal $\mathrm{CNC}$ morphogenesis and myocardial dysfunction during embryogenesis. An inductive interaction between $\mathrm{CNC}$ and the epicardium is an attractive concept for integrating the various structural and functional defects, but presently there is only limited experimental support[122]. Similarly, a greater understanding of the recent proposed dynamic intracellular (possibly reciprocal) signaling between the CNC-AHF lineages is likely to be important for complete insight into the actual functional mechanism of the $\mathrm{CNC}$ within the heart. Reliable and restricted epicardial Cre-expressing mice, in conjunction with AHF-restricted Cre mice, in various combinations may be required to determine whether alteration of epicardial and/or AHF gene expression and function can be affected by CNC defects. Subsequent myocardial defects caused by a lack of appropriate epicardial and/or AHF signals might then account for ventricular dysfunction. With the likely future identification of CNC-restricted and postmigratory CNC markers, subsequent tissue-restricted and inducible targeting approaches will help to further discriminate the primary from the secondary nonspecific cardiovascular effects. The identification of several unexpected derivatives of the $\mathrm{CNC}$ and the possibility that pluripotent $\mathrm{CNC}$ reside within the heart chambers all require ongoing investigation.

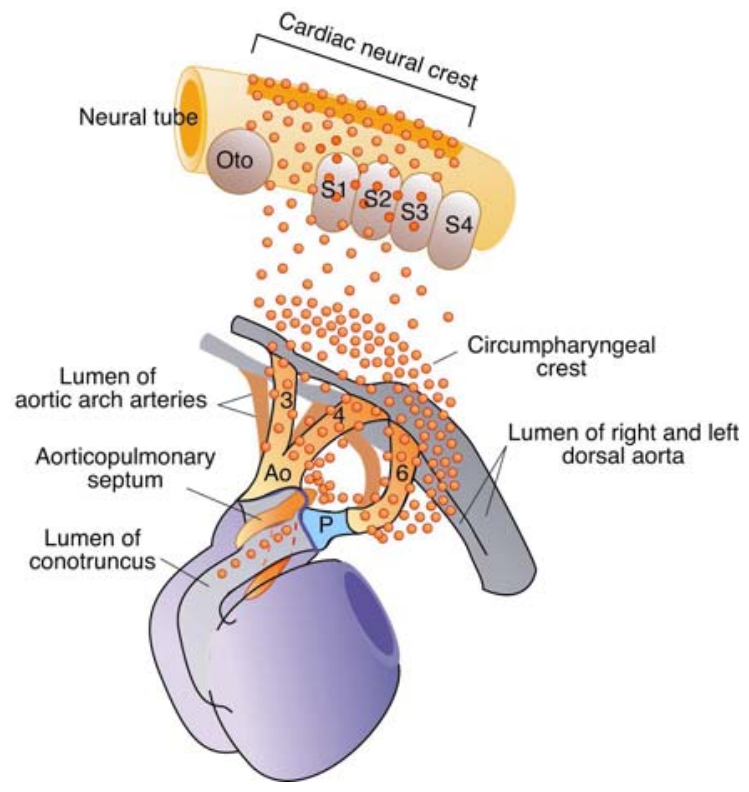

FIGURE 5. Schematic representation of migration of the CNC to the circumpharyngeal ridge, caudal pharyngeal arches (third, fourth, and sixth), and OFT prior to asymmetrical remodeling of the aortic arch arteries. Note that some of the CNC migrate in and surround the nascent aortic arch arteries, while others continue to migrate and eventually colonize the aorticopulmonary septum. Abbreviations: S1, S2, S3, S4, somites 1-4; Oto, otic vesicle. (From Kirby[170], with permission.) 
TABLE 1

Critical requirement of Cardiac NC

\begin{tabular}{|c|c|c|c|}
\hline $\begin{array}{l}\text { Putative } \\
\text { CNC Role }\end{array}$ & Genes & Loss and Gain-of-Function Cardiovascular Effects & Ref. \\
\hline \multirow[t]{6}{*}{ Specification } & Pax3 & $\begin{array}{l}\text { Homozygous embryos have PTA and VSD and die } \sim \text { E14 due to } \\
\text { myocardial dysfunction. }\end{array}$ & 23,24 \\
\hline & Wnt1/Wnt3a & $\begin{array}{l}\text { Double nulls fail to undergo NC expansion and have CNC cells } \\
\text { stuck in the NT and die } \sim \text { E18.5. }\end{array}$ & 34 \\
\hline & PO & $\begin{array}{l}\text { Useful marker of NC starting E9.0. Knockout mice are viable, } \\
\text { but have abnormal NC-derived Schwann cells. }\end{array}$ & 17,138 \\
\hline & $A p 2 \alpha$ & $\begin{array}{l}\text { Expressed in cardiac and cranial NC. Null mice die perinatally } \\
\text { and exhibit defects in the OFT, NT, craniofacial skeleton, eye, } \\
\text { and cranial ganglia. }\end{array}$ & 139 \\
\hline & Msx2 & $\begin{array}{l}\text { Knockout mice are viable, but have defects in skull ossification, } \\
\text { calvarial bones, teeth, and mammary glands. Pax3/Msx2 } \\
\text { double nulls rescue Pax3 mutant OFT defects, but still have } \\
\text { defects in muscles and NT. }\end{array}$ & 37,140 \\
\hline & Msx1/Msx2 & $\begin{array}{l}\text { Mice homozygous for mutations in both genes die } \sim \text { E18.0 with } \\
\text { craniofacial malformations, dysmorphogenesis of pharyngeal } \\
\text { derivatives, and anomalies in the conotruncal structures of the } \\
\text { heart. }\end{array}$ & 141 \\
\hline \multirow[t]{7}{*}{ EMT } & Snail (Snai1) & $\begin{array}{l}\text { Homozygous mutants die } \sim \text { E8.0 with defects in gastrulation and } \\
\text { lack mesoderm. Ectopic expression in the chick hindbrain } \\
\text { increases NC cell production. }\end{array}$ & $142,143,144$ \\
\hline & Slug (Snai2) & $\begin{array}{l}\text { Knockout mice are viable, although they exhibit postnatal } \\
\text { growth deficiency. Conversely, incubation with antisense } \\
\text { oligonucleotides in chick embryos results in failure of } \\
\text { presumptive NC to transform into mesenchyme. }\end{array}$ & $145,146,147$ \\
\hline & Id2 & $\begin{array}{l}\text { Mutant mice are in utero viable, however, ectopic expression of } \\
\text { Id } 2 \text { in chick embryos results in conversion of ectodermal cells } \\
\text { to NC cells. }\end{array}$ & $148,149,150$ \\
\hline & Pinch-1 & $\begin{array}{l}\text { Mull mice die } \sim E 6.5 \text { and overexpression in chick neural fold } \\
\text { explants halts NC cell migration. }\end{array}$ & 41,151 \\
\hline & RhoB & $\begin{array}{l}\text { Chick neural tube explants treated with C3 exotoxin inhibit } \\
\text { RhoB activity and prevent NC delamination. }\end{array}$ & 43 \\
\hline & Foxd3 & $\begin{array}{l}\text { Null mice die } \sim \text { E6.0 with an expansion of the extraembryonic } \\
\text { ectoderm and loss of pluripotent epiblast. Ectopic expression } \\
\text { in chick neural tubes induces NC marker expression, } \\
\text { promotes delamination and NC migration. }\end{array}$ & 152,153 \\
\hline & Sox9 & $\begin{array}{l}\text { Null embryos die } \sim \text { E11.5 from congestive heart failure due to } \\
\text { dilated major blood vessels. Null embryos exhibit hypoplasia } \\
\text { of the branchial arches. Conditional Wnt1-Cre deletion results } \\
\text { in NC apoptosis just before or just after migration into the } \\
\text { periphery. }\end{array}$ & 44,154 \\
\hline \multirow[t]{2}{*}{ Migration } & $C \times 43 a 1$ & $\begin{array}{l}\text { Knockouts have enlargement of the right ventricle, attenuation } \\
\text { of ductus arteriosus, abnormal myocardial development in the } \\
\text { conotruncus, and die birth due to pulmonary OFT } \\
\text { obstruction. }\end{array}$ & 47 \\
\hline & N-cadherin & $\begin{array}{l}\text { Homozygous mutant mice die } \sim \text { E10.0. Conditional Wnt1-Cre } \\
\text { deletion results in lethality } \sim \text { E12.5-13.5 and the mutant mice } \\
\text { have OFT defects, including PTA and thin ventricular } \\
\text { myocardium with a detached epicardium. }\end{array}$ & 155,156 \\
\hline
\end{tabular}


TABLE 1 (continued)

\begin{tabular}{|c|c|c|c|}
\hline $\begin{array}{l}\text { Putative } \\
\text { CNC Role }\end{array}$ & Genes & Loss and Gain-of-Function Cardiovascular Effects & Ref. \\
\hline & Wnt11 & $\begin{array}{l}\text { Knockouts die } \sim 2 \text { days postpartum most likely due to cardiac } \\
\text { defects. Following injection of the dominant negative form into } \\
\text { dorsal blastomeres of Xenopus embryos, there is inhibition in } \\
\text { the migration of NC. }\end{array}$ & 52,157 \\
\hline \multirow[t]{3}{*}{$\begin{array}{l}\text { Aortic arch } \\
\text { remodeling }\end{array}$} & Pdgf receptor $\alpha$ & $\begin{array}{l}\text { Most null mice die } \sim \text { E16.5 due to extensive hemorrhaging. } \\
\text { Conditional Wnt1-Cre studies results in neonatal lethality with } \\
\text { cleft palate, aortic arch artery defects, VSD, and OFT defects, } \\
\text { including PTA. }\end{array}$ & 65,158 \\
\hline & Alk2 & $\begin{array}{l}\text { Mutant mice die }- \text { E9.5 and severe disruption of mesoderm } \\
\text { formation. Conditional Wnt1-Cre analysis revealed that } \\
\text { mutants have deficiencies in NC cell migration to the OFT, } \\
\text { lack of NC-derived smooth muscle around the aortic arch } \\
\text { arteries with abnormal regression of the third and sixth aortic } \\
\text { arch arteries, and PTA. }\end{array}$ & $66,159,160$ \\
\hline & Alk5 & $\begin{array}{l}\text { Deletion of Alk5 in NC cells with Wnt1-Cre causes death in } \\
\text { mutant mice perinatally. PTA, inappropriate arch artery } \\
\text { remodeling and aortic sac development, and abnormal } \\
\text { thymus and parathyroids are present. }\end{array}$ & 67 \\
\hline \multirow[t]{11}{*}{$\begin{array}{l}\text { Arterial tree } \\
\text { remodeling }\end{array}$} & Foxc1/Foxc2 & $\begin{array}{l}\text { Double null mutants die } \sim \mathrm{E} 9.5 \text {, lack both an OFT and right } \\
\text { ventricle, exhibit NC apoptosis resulting in a spectrum of NC- } \\
\text { related defects. }\end{array}$ & 161 \\
\hline & Hand1 & $\begin{array}{l}\text { Homozygous embryos die } \sim \text { E8.5-9.5 and exhibit yolk sac } \\
\text { abnormalities as a result of mesoderm deficiency and } \\
\text { undergo abnormal heart looping. }\end{array}$ & 162 \\
\hline & Hand2 & $\begin{array}{l}\text { Null mutants die } \sim \text { E10.5 due to cardiac failure, lack of aortic } \\
\text { arch vessels, absent right ventricle, thin myocardium, and an } \\
\text { absence of trabeculation. }\end{array}$ & 163 \\
\hline & Vegf-A & $\begin{array}{l}\text { Mice lacking Vegf-A die prior to postnatal day } 14 \text { and have } \\
\text { enlarged hearts with irregular heartbeat and weak } \\
\text { contractions, impaired myocardial angiogenesis, aortic arch } \\
\text { artery defects, and fatal ischemic cardiomyopathy. }\end{array}$ & 164 \\
\hline & Neuropilin-1 & $\begin{array}{l}\text { Most null mice die } \sim \text { E13.5 and have transposition of the aortic } \\
\text { arch arteries, PTA, and disorganized yolk sac. }\end{array}$ & 165 \\
\hline & $M e f 2 c$ & $\begin{array}{l}\text { Homozygous mutants die } \sim \mathrm{E} 9.5 \text { and have a lack of smooth } \\
\text { muscle cell differentiation, absent right ventricle, and failure of } \\
\text { vascular remodeling in the yolk sac. }\end{array}$ & 80,166 \\
\hline & Tissue factor & $\begin{array}{l}\text { Null mutants die } \sim \text { E9.5-10.5, exhibit an abnormal yolk sac } \\
\text { circulation, and deficiency of smooth muscle cells in vitelline } \\
\text { vessels. }\end{array}$ & 81 \\
\hline & Endothelin-1 & $\begin{array}{l}\text { Homozygous mutants have aortic arch artery and OFT defects, } \\
\text { VSD, and enlarged right ventricle. }\end{array}$ & 83 \\
\hline & Ece-1 & $\begin{array}{l}\text { Knockouts have cardiac OFT defects, perimembranous VSD, } \\
\text { abnormal remodeling/regression of great vessels, and lack } \\
\text { enteric neurons and epidermal melanocytes. }\end{array}$ & 53 \\
\hline & EtA & $\begin{array}{l}\text { Mutants are cyanotic due to a structural defect in the upper } \\
\text { airway and die shortly after birth. Mutants have defects in } \\
\text { aortic arch artery alignment, OFT development, and } \\
\text { craniofacial structures. }\end{array}$ & 84 \\
\hline & Semaphorin3c & $\begin{array}{l}\text { Mutants die shortly after birth and exhibit PTA and interruption } \\
\text { of the aortic arch. NC migration into the proximal OFT is } \\
\text { impaired. }\end{array}$ & 85 \\
\hline
\end{tabular}


TABLE 1 (continued)

\begin{tabular}{|c|c|c|c|}
\hline $\begin{array}{l}\text { Putative } \\
\text { CNC Role }\end{array}$ & Genes & Loss and Gain-of-Function Cardiovascular Effects & Ref. \\
\hline & $T b \times 1$ & $\begin{array}{l}\text { Homozygous nulls exhibit hypoplasia of the pharynx, abnormal } \\
\text { and ectopic NC migration within the aortic arch arteries } \\
\text { resulting in anomalous pharyngeal arch artery formation, } \\
\text { VSD, and lack OFT septation. }\end{array}$ & 57 \\
\hline & Fgf8 & $\begin{array}{l}\text { Hypermorphic mutants survive till term, but have small/absent } \\
\text { thymus, craniofacial abnormalities, and malformations of both } \\
\text { the aortic arch arteries and OFT. }\end{array}$ & 87 \\
\hline & Pitx2 & $\begin{array}{l}\text { Homozygous mutants die } \sim \text { E14.0-15.0, and have a failure of } \\
\text { the ventral body closure, right pulmonary isomerism, swelling } \\
\text { of the atrioventricular canals, tricuspid and mitral valve } \\
\text { defects, and double outlet right ventricle. }\end{array}$ & 167 \\
\hline \multirow[t]{2}{*}{$\begin{array}{l}\text { Myocardial } \\
\text { development }\end{array}$} & Lbx1 & $\begin{array}{l}\text { Homozygous nulls defective heart looping and increased } \\
\text { proliferation resulting in myocardial hyperplasia. }\end{array}$ & 117 \\
\hline & p57Kip2 & $\begin{array}{l}\text { Mutants have umbilical abnormalities, defects in position of } \\
\text { body wall muscles, cleft palate, gastrointestinal defects, and } \\
\text { die just after birth. This is a useful marker of ventricular } \\
\text { trabecular development. }\end{array}$ & 168,169 \\
\hline
\end{tabular}

\section{ACKNOWLEDGMENTS}

The Wnt1-Cre mice were generously provided by Henry Sucov. We are grateful to the TheScientificWorld editorial team for their invitation to write this review and useful suggestions. While we have tried to review as much of the current cardiovascular NC development literature as comprehensively as possible, we regret that our review cannot include all of the field's many exciting findings. Our studies are supported, in part, by NIH T32 HL079995 postdoctoral support to PS; NIH grants HL061677 to ABF and HL60714 to SJC; and Riley Children's Foundation, Lilly Endowment, and IU Department of Pediatrics/Cardiology support for ABF and SJC.

\section{REFERENCES}

1. Le Douarin, N.M. and Kalcheim, C. (1999). In: Le Douarin NM, Kalcheim C, editors. The neural crest. Cambridge, UK: Cambridge University Press.

2. Knecht, A.K. and Bronner-Fraser, M. (2002). Induction of the neural crest: a multigene process. Nat Rev Genet. 3(6), 453-461.

3. Trainor, P.A., Ariza-McNaughton, L., and Krumlauf, R. (2002). Role of the isthmus and FGFs in resolving the paradox of neural crest plasticity and prepatterning. Science. 295(5558), 1288-1291.

4. Creazzo, T.L., Godt, R.E., Leatherbury, L., Conway, S.J., and Kirby, M.L. (1998). Role of cardiac neural crest cells in cardiovascular development. Annu Rev Physiol 60, 267-286.

5. Martinsen, B.J. and Bronner-Fraser, M. (1998). Neural crest specification regulated by the helix-loop-helix repressor Id2. Science 281(5379), 988-991.

6. Martinsen, B.J., Groebner, N.J., Frasier, A.J., and Lohr, J.L. (2003). Expression of cardiac neural crest and heart genes isolated by modified differential display. Gene Expr Patterns. 3(4), 407-411.

7. Maschhoff, K.L. and Baldwin, H.S. (2000). Molecular determinants of neural crest migration. American Journal of Medical Genetics, 97(4), 280-288.

8. Kirby, M.L. Contribution of neural crest to heart and vessel morphology. In: R.P. Harvey and N. Rosenthal, Editors, Heart development, Academic Press, Boston (1999), pp. 179-193

9. Kirby, M.L. (2002). Molecular embryogenesis of the heart. Pediat Dev Pathol 5(6), 516-543. 
10. Huston, M.R. and Kirby, M.L. (2003). Neural crest and cardiovascular development: a 20-year perspective. Birth Defects Res C Embryo Today, 69(1), 2-13.

11. Martinsen, B.J. (2005). Reference guide to the stages of chick heart embryology. Dev Dyn 233(4), $1217-1237$.

12. Gittenberger-de Groot, A.C., Bartelings, M.M., Deruiter, M.C., and Poelmann, R.E. (2005). Basics of cardiac development for the understanding of congenital heart malformations. Pediat Res. 57(2), 169-176.

13. Le Douarin, N.M. and Teillet, M.A. (1974). Experimental analysis of the migration and differentiation of neuroblasts of the autonomic nervous system and of neurectodermal mesenchymal derivatives, using a biological cell marking technique. Dev Biol. 41(1), 162-184.

14. Le Douarin, N.M. (1986). Cell line segregation during peripheral nervous system ontogeny. Science. 231(4745), 15151522.

15. Waldo, K.L., Lo, C.W., and Kirby, M.L. (1999) Connexin 43 expression reflects neural crest patterns during cardiovascular development. Dev Biol., 208(2), 307-323.

16. Kirby, M.L., Gale, T.F., and Stewart, D.E. (1983). Neural crest cells contribute to aorticopulmonary septation. Science 220, 1059-1061.

17. Yamauchi, Y., Abe, K., Mantani, A., Hitoshi, Y., Suzuki, M., Osuzu, F., Kuratani, S., and Yamamura, K. (1999). A novel transgenic technique that allows specific marking of the neural crest cell lineage in mice. Dev Biol. 212(1), 191203.

18. Jiang, X., Rowitch, D.H., Soriano, P., McMahon, A.P., and Sucov, H.M. (2000). Fate of the mammalian cardiac neural crest. Development, 127(8), 1607-1616.

19. Epstein, J.A., Li, J., Lang, D., Chen, F., Brown, C.B., Jin, F., Lu, M.M., Thomas, M., Liu, E., Wessels, A., and Lo, C.W. (2000). Migration of cardiac neural crest cells in Splotch embryos. Development, 127(9), 1869-1878.

20. Kirby, M.L., Hunt, P., Wallis, K., and Thorogood, P. (1997). Normal development of the cardiac outflow tract is not dependent on normal patterning of the aortic arch arteries. Dev Dyn 208, 34-47.

21. Conway, S.J., Bundy, J., Chen, J., Dickman, E., Rogers, R., and Will, B.M. (2000). Abnormal neural crest stem cell expansion is responsible for the conotruncal heart defects within the Splotch $\left(\mathrm{Sp}^{2 \mathrm{H}}\right)$ mouse mutant. Cardiovascular Research, 47, 314-328.

22. Epstein, J.A. and Buck, C.A. (2000). Transcriptional regulation of cardiac development: implications for congenital heart disease and DiGeorge syndrome. Pediatr Res. 48(6), 717-724.

23. Conway, S.J., Henderson, D.J., and Copp, A.J. (1997). Pax3 is required for cardiac neural crest migration in the mouse: evidence for the $\left(\mathrm{Sp}^{2 \mathrm{H}}\right)$ mutant. Development, 124, 505-514.

24. Conway, S.J., Godt, R.E., Hatcher, C., Leatherbury, L., Zolotouchnikov, V.V., Brotto, M.A.P., Copp, A.J., Kirby, M.L., and Creazzo, T.L. (1997). Neural crest is involved in development of abnormal myocardial function. Journal of Molecular and Cellular Cardiology, 29, 2675-2685.

25. Franz, T. (1989). Persistent truncus arteriosus in the Splotch mutant mouse. Anat Embryol (Berl). 180(5), $457-464$.

26. Conway, S.J., Henderson, D.J., Kirby, M.L., Anderson, R.H., and Copp, A.J. (1997). Development of a lethal congenital heart defect in the splotch (Pax3) mutant mouse. Cardiovasc Res 36, 163-173.

27. Dickman, E.D., Rogers, R., and Conway, S.J. (1999). Abnormal skeletogenesis occurs coincident with increased apoptosis in the Splotch (Sp2H) mutant: putative roles for Pax3 and PDGFRalpha in rib patterning. Anat Rec. 255(3), 353-361.

28. Schubert, F.R., Tremblay, P., Mansouri, A., Faisst, A.M., Kammandel, B., Lumsden, A., Gruss, P., and Dietrich, S. (2001). Early mesodermal phenotypes in splotch suggest a role for Pax3 in the formation of epithelial somites. Dev Dyn. 222(3), 506-521.

29. Goulding, M., Sterrer, S., Fleming, J., Balling, R., Nadeau, J., Moore, K.J., Brown, S.D., Steel, K.P., and Gruss, P. (1993). Analysis of the Pax-3 gene in the mouse mutant splotch. Genomics. 17(2), 355-363.

30. Tassabehji, M., Newton, V.E., Leverton, K., Turnbull, K., Seemanova, E., Kunze, J., Sperling, K., Strachan, T., and Read, A.P. (1994). PAX3 gene structure and mutations: close analogies between Waardenburg syndrome and the Splotch mouse. Hum Mol Genet. 3(7), 1069-1074.

31. Banerjee, AK. (1986). Waardenburg's syndrome associated with ostium secundum atrial septal defect. J. R. Soc. Med. 79, 677-678.

32. Mathieu, M., Bourges, E., Caron, F. and Piussan, C. (1990). Waardenburg's syndrome and severe cyanotic cardiopathy. Arch. Fr. Pediatr. 47, 657-659.

33. Dorsky, R.I., Moon, R.T., and Raible, D.W. (1998). Control of neural crest cell fate by the Wnt signalling pathway. Nature. 396(6709), 370-373.

34. Ikeya, M., Lee, S.M., Johnson, J.E., McMahon, A.P., and Takada, S. (1997). Wnt signalling required for expansion of neural crest and CNS progenitors. Nature. 389(6654), 966-970.

35. Saint-Jeannet, J.P., He, X., Varmus, H.E., and Dawid, I.B. (1997). Regulation of dorsal fate in the neuraxis by Wnt-1 and Wnt-3a. Proc Natl Acad Sci U S A. 94(25), 13713-13718.

36. Li, J., Liu, K.C., Jin, F., Lu, M.M., and Epstein, J.A. (1999). Transgenic rescue of congenital heart disease and spina bifida in Splotch mice. Development 126(11), 2495-2503.

37. Kwang, S.J., Brugger, S.M., Lazik, A., Merrill, A.E., Wu, L.Y., Liu, Y.H., Ishii, M., Sangiorgi, F.O., Rauchman, M., Sucov, H.M., Maas, R.L., and Maxson, R.E. Jr. (2002). Msx2 is an immediate downstream effector of Pax3 in the development of the murine cardiac neural crest. Development 129(2), 527-538. 
38. Duband, J.L., Monier, F., Delannet, M., and Newgreen, D. (1995). Epithelium-mesenchyme transition during neural crest development. Acta Anat (Basel). 154(1), 63-78.

39. Bolos, V., Peinado, H., Perez-Moreno, M.H., Fraga, M.F., Esteller, M., and Cano, A. (2003). The transcription factor Slug represses E-cadherin expression and induces epithelial to mesenchymal transitions: a comparison with Snail and E47 repressors, J. Cell Sci. 116, 499-511.

40. Cano, A., Pérez, M.A., Rodrigo, I., Locascio, A., Blanco, M.J., Del Barrio, M., Portillo, F., and Nieto, M.A. (2000). The transcription factor Snail controls epithelial-mesenchymal transitions by repressing E-cadherin expression, Nat. Cell Biol. 2, 76-83.

41. Martinsen, B.J., Neumann, A.N., Frasier, A.J., Baker, C.V.H., Krull, C.E., and Lohr, J.L. (2006). Pinch-1 expression during early avian embryogenesis: Implications for neural crest and heart development. Dev. Dyn. 235, 152-162.

42. Akitaya, T. and Bronner-Fraser, M. (1992). Expression of cell adhesion molecules during initiated and cessation of neural crest migration, Dev. Dyn. 194, 12-20.

43. Liu, J. and Jessell, T. (1998). A role for RhoB in the delamination of neural crest cells from the dorsal neural tube, Development 125, 5055-5067.

44. Cheung, M., Chaboissier, M.C., Mynett, A., Hirst, E., Schedl, A., and Briscoe, J. (2005). The transcriptional control of trunk neural crest induction, survival, and delamination. Dev Cell. 8(2), 179-192.

45. Lumsden, A., Sprawson, N., and Graham, A. (1991). Segmental origin and migration of neural crest cells in the hindbrain region of the chick embryo. Development. 113(4), 1281-1291.

46. Lo, C.W., Waldo, K.L. and Kirby, M.L. (1999). Gap junction communication and the modulation of cardiac neural crest cells. Trends Cardiovasc. Med. 9, 63-69.

47. Huang, G.Y., Wessels, A., Smith, B.R., Linask, K.K., Ewart, J.L. and Lo, C.W. (1998). Alteration in connexin 43 gap junction gene dosage impairs conotruncal heart development. Dev. Biol. 198, 32-44.

48. Li, W.E., Waldo, K., Linask, K.L., Chen, T., Wessels, A., Parmacek, M.S., Kirby, M.L. and Lo, C.W. (2002). An essential role for connexin43 gap junctions in mouse coronary artery development. Development 129, 2031-2042.

49. Xu, X., Francis, R., Wei, C.J., Linask, K.L., and Lo, C.W. (2006). Connexin 43-mediated modulation of polarized cell movement and the directional migration of cardiac neural crest cells. Development. 133(18), 3629-3639.

50. Xu, X., Li, W.E., Huang, G.Y., Meyer, R., Chen, T., Luo, Y., Thomas, M.P., Radice, G.L. and Lo, C.W. (2001) Modulation of mouse neural crest cell motility by N-cadherin and connexin 43 gap junctions. J. Cell Biol. 154, 217 230.

51. Luo, Y., High, F.A., Epstein, J.A., and Radice, G.L. (2006). N-cadherin is required for neural crest remodeling of the cardiac outflow tract. Dev Biol. 299(2), 517-528.

52. De Calisto, J., Araya, C., Marchant, L., Riaz, C.F., and Mayor, R. (2005). Essential role of non-canonical Wnt signaling in neural crest migration. Development. 132(11), 2587-2597.

53. Yanagisawa, H., Hammer, R.E., Richardson, J.A., Williams, S.C., Clouthier, D.E., and Yanagisawa, M. (1998). Role of Endothelin-1/Endothelin-A receptor-mediated signaling pathway in the aortic arch patterning in mice. J Clin Invest 102(1), 22-33.

54. Le Lievre, C.S. and Le Douarin, N.M. (1975). Mesenchymal derivatives of the neural crest: analysis of chimaeric quail and chick embryos. J Embryol Exp Morphol 34(1), 125-154.

55. Fishman, M.C. and Kirby, M.L. (1998). Fallen arches, or how the vertebrate got its head. J Clin Invest 102(1), 1-3.

56. Wendling, O., Dennefeld, C., Chambon, P., and Mark, M. (2000). Retinoid signaling is essential for patterning the endoderm of the third and fourth pharyngeal arches. Development 127(8), 1553-1562.

57. Vitelli, F., Morishima, M., Taddei, I., Lindsay, E.A., and Baldini, A. (2002). Tbx1 mutation causes multiple cardiovascular defects and disrupts neural crest and cranial nerve migratory pathways. Hum Mol Genet. 11(8), 915922.

58. Conway, S.J., Kruzynska-Frejtag, A., Kneer, P.L., Machnicki, M., and Koushik, S.V. (2002). What cardiovascular defect does my prenatal mouse mutant have, and why? Genesis, 34, 1-21.

59. Olson, E.N. and Srivastava, D. (1996). Molecular pathways controlling heart development. Science 272(5262), 671676.

60. Ciment, G. and Weston, J.A. (1985). Segregation of developmental abilities in neural-crest-derived cells: identification of partially restricted intermediate cell types in the branchial arches of avian embryos. Dev Biol. 111(1), 73-83.

61. Kirby, M.L. and Waldo, K. (1995). Neural crest and cardiovascular patterning. Circ Res 77, 211-215.

62. Kirby, M.L. and Waldo, K.L. (1990). Role of neural crest in congenital heart disease. Circulation 82, 332-340.

63. Erickson, C.A. and Perris, R. (1993). The role of cell-cell and cell-matrix interactions in the morphogenesis of the neural crest. Dev Biol. 159(1), 60-74.

64. Henderson, D.J. and Copp, A.J. (1997). Role of the extracellular matrix in neural crest cell migration. J Anat 191 (Pt 4), 507-515.

65. Tallquist, M.D. and Soriano, P. (2003). Cell autonomous requirement for PDGFRalpha in populations of cranial and cardiac neural crest cells. Development. 130(3), 507-518.

66. Wang, J., Nagy, A., Larsson, J., Dudas, M., Sucov, H.M., and Kaartinen, V. (2006). Defective ALK5 signaling in the neural crest leads to increased postmigratory neural crest cell apoptosis and severe outflow tract defects.BMC Dev Biol. 6(51). 
67. Kaartinen, V., Dudas, M., Nagy, A., Sridurongrit, S., Lu, M.M., and Epstein, J.A. (2004). Cardiac outflow tract defects in mice lacking ALK2 in neural crest cells. Development. 131(14), 3481-3490.

68. Srivastava, D. (2001). Genetic assembly of the heart: implications for congenital heart disease. Annu Rev Physiol 63, 451-469.

69. Broekhuizen, M.L., Gittenberger-de Groot, A.C., Baasten, M.J., Wladimiroff, J.W., and Poelmann, R.E. (1998). Disturbed vagal nerve distribution in embryonic chick hearts after treatment with all-trans retinoic acid. Anat Embryol (Berl). 197(5), 391-397.

70. Hogers, B., DeRuiter, M.C., Gittenberger-de Groot, A.C., and Poelmann, R.E. (1999). Extraembryonic venous obstructions lead to cardiovascular malformations and can be embryolethal. Cardiovasc Res 41(1), 87-99.

71. Hunter, E.S., 3rd., Rogers, E.H., Schmid, J.E., and Richard, A. (1996). Comparative effects of haloacetic acids in whole embryo culture. Teratology 54(2), 57-64.

72. Sulik, K.K., Johnston, M.C., Daft, P.A., Russell, W.E., and Dehart, D.B. (1986). Fetal alcohol syndrome and DiGeorge anomaly: critical ethanol exposure periods for craniofacial malformations as illustrated in an animal model. Am J Med Genet Suppl 2, 97-112.

73. Baldwin, H.S. (1999). Advances in understanding the molecular regulation of cardiac development. Curr Opin Pediatr. 11(5), 413-418.

74. Stoller, J.Z. and Epstein, J.A. (2005). Cardiac neural crest. Semin Cell Dev Biol. 16(6), 704-715.

75. Winnier, G., Kume, T., Deng, K., Rogers, R., Bundy, J., Raines, C., Hogan, B.L.M., and Conway, S.J. (1999). Roles for the winged helix transcription factors MF1 and MFH1 in cardiovascular development revealed by non-allelic noncomplementation of null alleles. Developmental Biolog. 216, 16-27.

76. Merscher, S., Funke, B., Epstein, J.A., Heyer, J., Puech, A., Lu, M.M., Xavier, R.J., Demay, M.B., Russell, R.G., Factor, S., Tokooya, K., Jore, B.S., Lopez, M., Pandita, R.K., Lia, M., Carrion, D., Xu, H., Schorle, H., Kobler, J.B., Scambler, P., Wynshaw-Boris, A., Skoultchi, A.I., Morrow, B.E., and Kucherlapati, R. (2001). TBX1 is responsible for cardiovascular defects in velo-cardio-facial/DiGeorge syndrome. Cell 104(4), 619-629.

77. Firulli, A.B. and Conway, S.J. (2004). Combinatorial transcriptional interaction within the cardiac neural crest: a pair of HANDs in heart formation. Birth Defects Res C Embryo Today. 72(2), 151-161.

78. Carmeliet, P., Moons, L., Luttun, A., Vincenti, V., Compernolle, V., De Mol, M., Wu, Y., Bono, F., Devy, L., Beck, H., Scholz, D., Acker, T., DiPalma, T., Dewerchin, M., Noel, A., Stalmans, I., Barra, A., Blacher, S., Vandendriessche, T., Ponten, A., Eriksson, U., Plate, K.H., Foidart, J.M., Schaper, W., Charnock-Jones, D.S., Hicklin, D.J., Herbert, J.M., Collen, D., and Persico, M.G. (2001). Synergism between vascular endothelial growth factor and placental growth factor contributes to angiogenesis and plasma extravasation in pathological conditions. Nat. Med. 7, 575-583. Stalmans,, I., Lambrechts, D., Desmet, F., Jansen, S., Wang, J., Maity, S., Kneer, P., von der Ohe, M., Swillen, A., Maes, C., Molin, D., Hellings, P., Boetel, T., Haardt, M., Compernolle, V., Dewerchin, M., Emanuel, B., Gittenbergerde Groot, A., Esguerra, C., Scambler, P., Morrow, B., Driscol, D., Moons, L., Carmeliet, G., Behn-Krappa, A., Devriendt, K., Collen, D., Conway, S.J. and Carmeliet, P. (2003). VEGF: a modifier of the del22q11 (DiGeorge) syndrome? Nature Medicine, 9, 173-182.

80. Lin, Q., Lu, J., Yanagisawa, H., Webb, R., Lyons, G.E., Richardson, J.A., and Olson, E.N. (1998). Requirement of the MADS-box transcription factor MEF2C for vascular development. Development 125, 4565-4574.

81. Carmeliet, P., Mackman, N., Moons, L., Luther, T., Gressens, P., Van Vlaenderen, I., Demunck, H., Kasper, M., Breier, G., Evrard, P., Muller, M., Risau, W., Edgington, T., and Collen, D. (1996). Role of tissue factor in embryonic blood vessel development. Nature 383, 73-75.

82. Noden, D.M. (1989). Embryonic origins and assembly of blood vessels. Am Rev Respir Dis 140, 1097-1103.

83. Kurihara, Y., Kurihara, H., Oda, H., Maemura, K., Nagai, R., Ishikawa, T., Yazaki, Y. (1995). Aortic arch malformations and ventricular septal defect in mice deficient in endothelin-1. J Clin Invest 96(1), 293-300.

84. Clouthier, D.E., Hosoda, K., Richardson, J.A., Williams, S.C., Yanagisawa, H., Kuwaki, T., Kumada, M., Hammer, R.E., and Yanagisawa, M. (1998). Cranial and cardiac neural crest defects in endothelin-A receptor-deficient mice. Development 125(5), 813-824.

85. Feiner, L., Webber, A.L., Brown, C.B., Lu, M.M., Jia, L., Feinstein, P., Mombaerts, P., Epstein, J.A., and Raper, J.A. (2001). Targeted disruption of semaphorin 3C leads to persistent truncus arteriosus and aortic arch interruption. Development 128, 3061-3070.

86. Garg, V., Yamagishi, C., Hu, T., Kathiriya, I.S., Yamagishi, H., and Srivastava, D. (2001). Tbx1, a DiGeorge syndrome candidate gene, is regulated by sonic hedgehog during pharyngeal arch development. Dev Biol. 235(1), 62-73.

87. Abu-Issa R, Smyth G, Smoak I, Yamamura K, Meyers EN. (2002). Fgf8 is required for pharyngeal arch and cardiovascular development in the mouse. Development. 129(19), 4613-4625.

88. Brown, C.B., Wenning, J.M. Lu, M.M., Epstein, D.J., Meyers, E.N., and Epstein, J.A. (2004). Cre-mediated excision of Fgf8 in the Tbx1 expression domain reveals a critical role for Fgf8 in cardiovascular development in the mouse. Dev Biol. 267(1), 190-202.

89. Tiso, N., Filippi, A., Pauls, S., Bortolussi, M., and Argenton, F. (2002). BMP signalling regulates anteroposterior endoderm patterning in zebrafish. Mech Dev. 118(1-2), 29-37.

90. Bachiller, D., Klingensmith, J., Shneyder, N., Tran, U., Anderson, R., Rossant, J., and De Robertis, E.M. (2003). The role of chordin/Bmp signals in mammalian pharyngeal development and DiGeorge syndrome. Development. 130(15), 3567-3578. 
91. Iulianella, A., Lohnes, D., (2002). Chimeric.analysis of retinoic acid receptor function during cardiac looping. Dev. Biol. 247(1), 62-75.

92. Pennekamp, P., Karcher, C., Fischer, A., Schweickert, A., Skryabin, B., Horst, J., Blum, M., and Dworniczak, B. (2002). The ion channel polycystin-2 is required for left-right axis determination in mice. Curr Biol 12(11), 938-943.

93. Mercola, M. and Levin, M. (2001). Left-right asymmetry determination in vertebrates. Annual Review of Cell and Developmental Biology 17, 779-805.

94. Liu, C., Liu, W., Lu, M.F., Brown, N.A., and Martin, J.F. (2001). Regulation of left-right asymmetry by thresholds of Pitx2c activity. Development 128(11), 2039-2048.

95. Black BL. (2007). Transcriptional pathways in second heart field development. Semin Cell Dev Biol. 18(1), 67-76.

96. Poelmann, R.E. and Gittenberger-de Groot, A.C. (1999). A subpopulation of apoptosis-prone cardiac neural crest cells targets to the venous pole: multiple functions in heart development? Dev Biol. 207(2), 271-286.

97. Poelmann, R.E., Mikawa, T., and Gittenberger-de Groot, A.C. (1998). Neural crest cells in outflow tract septation of the embryonic chick heart: differentiation and apoptosis. Dev. Dyn. 212, 373-384.

98. Martinsen, B.J., Frasier, A.J., Baker, C.V., and Lohr, J.L. (2004). Cardiac neural crest ablation alters Id2 gene expression in the developing heart. Dev Biol. 272(1), 176-190.

99. Qayyum, S.R., Webb, S., Anderson, R.H., Verbeek, F.J., Brown, N.A., and Richardson, M.K. (2001). Septation and valvar formation in the outflow tract of the embryonic chick heart. Anat. Rec. 264, 273-283.

100. van Gijn, M.E., Blankesteijn, W.M., Smits, J.F., Hierck, B., and Gittenberger-de Groot, A.C. (2001). Frizzled 2 is transiently expressed in neural crest-containing areas during development of the heart and great arteries in the mouse. Anat Embryol (Berl). 203(3), 185-192.

101. van den Hoff, M.J., Moorman, A.F., Ruijter, J.M., Lamers, W.H., Bennington, R.W., Markwald. R.R., and Wessels, A. (1999). Myocardialization of the cardiac outflow tract. Dev Biol. 212(2), 477-490.

102. van den Hoff, M.J., and Moorman AF (2005). Wnt, a driver of myocardialization? Circ. Res. 96(3), $274-276$.

103. Phillips, H.M., Murdoch, J.N., Chaudhry, B., Copp, A.J., and Henderson, D.J. (2005). Vangl2 acts via RhoA signaling to regulate polarized cell movements during development of the proximal outflow tract. Circ Res. 96(3), 292-299.

104. Henderson, D.J., Phillips, H.M., and Chaudhry, B. (2006) Vang-like 2 and noncanonical Wnt signaling in OFT development. Trends in Cardiovascular Medicine. 16(2), 38-45.

105. Luo, Y., High, F.A., Epstein, J.A., and Radice, G.L. (2006). N-cadherin is required for neural crest remodeling of the cardiac OFT. Dev Biol. 299(2), 517-528.

106. Poelmann, R.E., Jongbloed, M.R., Molin, D.G., Fekkes, M.L., Wang, Z., Fishman, G.I., Doetschman, T., Azhar, M., Gittenberger-de Groot, A.C. (2004). The neural crest is contiguous with the cardiac conduction system in the mouse embryo: a role in induction? Anat Embryol (Berl). 208(5), 389-393.

107. Poelmann, R.E. and Gittenberger-de Groot, A.C. (1999). A subpopulation of apoptosis- prone cardiac neural crest cells targets to the venous pole: multiple functions in heart development? Dev Biol. 207(2), 271-286.

108. Nakamura, T., Colbert, M.C., and Robbins, J. (2006). Neural crest cells retain multipotential characteristics in the developing valves and label the cardiac conduction system. Circ Res. 98(12), 1547-1554.

109. Tomita, Y., Matsumura, K., Wakamatsu, Y., Matsuzaki, Y., Shibuya, I., Kawaguchi, H., Ieda, M., Kanakubo, S., Shimazaki, T., Ogawa, S., Osumi, N., Okano, H., and Fukuda, K. (2005). Cardiac neural crest cells contribute to the dormant multipotent stem cell in the mammalian heart. J Cell Biol. 170(7), 1135-1146.

110. Sohal, G.S., Ali, M.M., Ali, A.A., and Dai, D. (1999). Ventrally emigrating neural tube cells differentiate into heart muscle. Biochem Biophys Res Commun. 254, 601-604.

111. Yaneza, M., Gilthorpe, J.D., Lumsden, A., and Tucker, A.S. (2002). No evidence for ventrally migrating neural tube cells from the mid- and hindbrain. Dev Dyn 223, 163-167.

112. Boot, M.J., Gittenberger-de Groot, A.C., van Iperen, L., and Poelmann, R.E. (2003). The myth of ventrally emigrating neural tube (VENT) cells and their contribution to the developing cardiovascular system. Anat Embryol (Berl). 206(4), 327-333.

113. Kirby, M.L. (1988). Nodose placode provides ectomesenchyme to the developing chick heart in the absence of the cardiac neural crest. Cell Tissue Res. 252(1), 17-22.

114. Kochilas, L.K., Li, J., Jin, F., Buck, C.A., and Epstein, J.A. (1999). Kip2 expression is enhanced during mid-cardiac murine development and is restricted to trabecular myocardium. Pediatr Res. 45(1), 635-642.

115. Lagutina, I., Conway, S.J., Sublett, J. and Grosveld, G. (2002). PAX3-FKHR knock-in mice show developmental aberrations but do not develop tumors. Mol.Cell Biol., 22, 7204-7216.

116. Chalepakis, G., Jones, F.S., Edelman, G.M., and Gruss, P. (1994). Pax-3 contains domains for transcription activation and transcription inhibition. Proc Natl Acad Sci US A. 91(26), 12745-12749.

117. Schafer, K., Neuhaus, P., Kruse, J., and Braun, T. (2003). The homeobox gene Lbx1 specifies a subpopulation of cardiac neural crest necessary for normal heart development. Circ Res. 92(1), 73-80.

118. Gonzalez-Reyes, S., Fernandez-Dumont, V., Martinez-Calonge, W., Martinez, L. Hernandez, F., and Tovar, J. (2005). Pax3 mRNA is decreased in the hearts of rats with experimental diaphragmatic hernia. Pediatr Surg Int. 21(3), 203207.

119. Moore, A., McInnes, L., Kreidberg, J., Hastie N. and Schedl, A. (1999). YAC complementation shows a requirement for Wt1 in the development of epicardium, adrenal gland and throughout nephrogenesis, Development 126, $1845-1857$. 
120. Lavine, K.J., Yu, K., White, A.C., Zhang, X., Smith, C., Partanen, J., and Ornitz, D.M. (2005). Endocardial and epicardial derived FGF signals regulate myocardial proliferation and differentiation in vivo, Dev Cell 8, 85-95.

121. Engleka, K.A., Gitler, A.D., Zhang, M., Zhou, D.D., High, F.A., and Epstein, J.A. (2005). Insertion of Cre into the Pax3 locus creates a new allele of Splotch and identifies unexpected Pax3 derivatives. Dev Biol. 280(2), 396-406.

122. Chai, Y., Jiang, X., Ito, Y., Bringas, P., Jr,, Han, J., Rowitch, D.H., Soriano, P., McMahon, A.P., and Sucov, H.M. (2000). Fate of the mammalian cranial neural crest during tooth and mandibular morphogenesis. Development 127, 1671-1679.

123. Stottmann, R.W., Choi, M., Mishina, Y., Meyers, E.N., and Klingensmith, J. (2004). BMP receptor IA is required in mammalian neural crest cells for development of the cardiac OFT and ventricular myocardium. Development. 131(9), 2205-2218.

124. Farrell, M.J., Burch, J.L., Wallis, K., Rowley, L., Kumiski, D., Stadt, H., Godt, R.E., Creazzo, TL, and Kirby, M.L. (2001). FGF-8 in the ventral pharynx alters development of myocardial calcium transients after neural crest ablation. $J$ Clin Invest. 107(12), 1509-1517.

125. Kelly, R.G., Brown, N.A., and Buckingham, M.E. (2001). The arterial pole of the mouse heart forms from Fgf10expressing cells in pharyngeal mesoderm. Dev. Cell. 1, 435-440.

126. Cai, C.L, Liang, X., Shi, Y., Chu, P.H., Pfaff, S.L., Chen, J., and Evans, S. (2003). Isl1 identifies a cardiac progenitor population that proliferates prior to differentiation and contributes a majority of cells to the heart. Dev. Cell 5, 877889.

127. Kelly, R.G. and Buckingham, M.E. (2002). The anterior heart-forming field: voyage to the arterial pole of the heart. Trends Genet. 18, 210-216.

128. Ilagan, R., Abu-Issa, R., Brown, D., Yang, Y.P., Jiao, K., Schwartz, R.J., Klingensmith, J., and Meyers, E.N. (2006). Fgf8 is required for anterior heart field development. Development 133(12), 2435-2445.

129. Ward, C., Stadt, H., Hutson, M., and Kirby, M.L. (2005). Ablation of the secondary heart field leads to tetralogy of Fallot and pulmonary atresia. Dev. Biol. 284, 72-83.

130. Goddeeris, M.M., Schwartz, R., Klingensmith, J., and Meyers, E.N. (2007). Independent requirements for Hedgehog signaling by both the anterior heart field and neural crest cells for outflow tract development. Development. 134(8), 1593-1604.

131. Sato M, Yost HJ (2003). Cardiac neural crest contributes to cardiomyogenesis in zebrafish. Dev Biol. 257(1), $127-139$.

132. Li, Y.X., Zdanowicz, M., Young, L., Kumiski, D., Leatherbury, L., and Kirby, M.L. (2003). Cardiac neural crest in zebrafish embryos contributes to myocardial cell lineage and early heart function. Dev Dyn. 226(3), 540-550.

133. Sieber-Blum, M. (2004). Cardiac neural crest stem cells. Anat Rec A Discov Mol Cell Evol Biol. 276(1), 34-42.

134. Sieber-Blum, M. and Cohen, A.M. (1980). Clonal analysis of quail neural crest cells: they are pluripotent and differentiate in vitro in the absence of non-crest cells. Dev Biol. 80(1), 96-106.

135. Ito, K. and Sieber-Blum, M. (1993). Pluripotent and developmentally restricted neural-crest-derived cells in posterior visceral arches. Dev Biol 156, 191-200.

136. Bronner-Fraser, M. and Fraser, S.E. (1998). Cell lineage analysis reveals multipotency of some avian neural crest cells. Nature. 335(6186), 161-164.

137. Ito, K. and Sieber-Blum, M. (1991). In vitro clonal analysis of quail cardiac neural crest development. Dev Biol 148, 95-106.

138. Xu, W., Manichella, D., Jiang, H., Vallat, J.M., Lilien. J., Baron. P., Scarlato, G., Kamholz, J,, Shy, M.E. (2000). Absence of P0 leads to dysregulation of myelin gene expression and myelin morphogenesis. J Neurosci Res. 60(6), 714-724.

139. Brewer, S., Jiang, X., Donaldson, S., Williams, T., and Sucov, H. (2002). Requirement for AP-2 $\alpha$ in cardiac outflow tract morphogenesis. Mech of Dev. 110, 139-149.

140. Satokata, I., Ma, L., Ohshima, H., Bei, M., Woo, I., Nishizawa, K., Maeda, T., Takano, Y., Uchiyama, M., Heaney, S., Peters, H., Tang, Z., Maxson, R., and Maas, R. (2000). Msx2 deficiency in mice causes pleiotropic defects in bone growth and ectodermal organ formation. Nature Genetics. 24, 391-395.

141. Ishii, M., Han, J., Yen, H.Y., Sucov, H.M., Chai, Y., and Maxson, R.E. Jr. Combined deficiencies of Msx 1 and Msx2 cause impaired patterning and survival of the cranial neural crest. (2005). Development. 132(22), 4937-4950.

142. Carver, E.A., Jiang, R., Lan, Y., Oram, K.F., and Gridley, T. (2001). The mouse snail gene encodes a key regulator of the epithelial-mesenchymal transition. Mol Cell Biol. 21(23), 8184-8188.

143. Murray, S.A. and Gridley, T. (2006). Snail family genes are required for left-right asymmetry determination, but not neural crest formation, in mice. Proc Natl Acad Sci USA. 103(27), 10300-10304.

144. Barrio, M.G. and Nieto, M.A. (2002). Overexpression of Snail family members highlights their ability to promote chick neural crest formation. Development. 129(7), 1583-1593.

145. Jiang, R., Lan, Y., Norton, C.R., Sundberg, J.P., and Gridley, T. (1998). The Slug gene is not essential for mesoderm or neural crest development in mice. Dev Biol. 198(2), 277-285.

146. Nieto, M.A., Sargent, M.G., Wilkinson, D.G., and Cooke, J. (1994). Control of cell behavior during vertebrate development by Slug, a zinc finger gene. Science. 264(5160), 835-839.

147. Romano, L.A. and Runyan, R.B. (1999). Slug is a mediator of epithelial-mesenchymal cell transformation in the developing chicken heart. Dev Biol. 212(1), 243-254. 
148. Sugai, M., Gonda, H., Kusunoki, T., Katakai, T., Yokota, Y., and Shimizu, A. (2003). Essential role of Id2 in negative regulation of IgE class switching. Nat Immunol. 4(1), 25-30.

149. Murphy, D.J., Swigart, L.B., Israel, M.A., and Evan, G.I. (2004). Id2 is dispensable for Myc- induced epidermal neoplasia. Mol Cell Biol. 24(5), 2083-2090.

150. Martinsen, B.J. and Bronner-Fraser, M. (1998). Neural crest specification regulated by the helix-loop-helix repressor Id2. Science. 281(5379), 988-991.

151. Liang, X., Zhou, Q., Li, X., Sun, Y., Lu, M., Dalton, N., Ross, J. Jr,, and Chen, J. (2005). PINCH1 plays an essential role in early murine embryonic development but is dispensable in ventricular cardiomyocytes. Mol Cell Biol. 25(8), 3056-3030.

152. Tompers, D.M., Foreman, R.K., Wang, Q., Kumanova, M., and Labosky, P.A. (2005). Foxd3 is required in the trophoblast progenitor cell lineage of the mouse embryo. Dev Biol. 285(1), 126-137.

153. Dottori, M., Gross, M.K., Labosky, P., and Goulding, M. (2001). The winged-helix transcription factor Foxd3 suppresses interneuron differentiation and promotes neural crest cell fate. Development 128(21), 4127-4138.

154. Akiyama, H., Chaboissier, M.C., Behringer, R.R., Rowitch, D.H., Schedl, A., Epstein, J.A, and de Crombrugghe, B. (2004). Essential role of Sox9 in the pathway that controls formation of cardiac valves and septa. Proc Natl Acad Sci USA. 101(17), 6502- 6507.

155. Radice, G.L., Rayburn, H., Matsunami, H., Knudsen, K.A, Takeichi, M., and Hynes, R.O. (1997). Developmental defects in mouse embryos lacking N-cadherin. Dev Biol. 181(1), 64-78.

156. Luo, Y., High, F.A., Epstein, J.A., and Radice, G.L. (2006). N-cadherin is required for neural crest remodeling of the cardiac outflow tract. Dev Biol. 299(2), 517-528.

157. Majumdar, A., Vainio, S., Kispert, A., McMahon, J., McMahon, A.P. (2003). Wnt11 and Ret/Gdnf pathways cooperate in regulating ureteric branching during metanephric kidney development. Development. 130(14), 3175-3185.

158. Soriano P. (1997). The PDGF alpha receptor is required for neural crest cell development and for normal patterning of the somites. Development. 124(14), 2691-2700.

159. Gu, Z., Reynolds, E.M., Song, J., Lei, H., Feijen, A., Yu, L., He, W., MacLaughlin, D.T., van den Eijnden-van Raaij, J., Donahoe, P.K., and Li, E. (1999). The type I serine/threonine kinase receptor ActRIA (ALK2) is required for gastrulation of the mouse embryo. Development. 126(11), 2551-2561.

160. Mishina, Y., Crombie, R., Bradley, A., and Behringer, R.R. (1999). Multiple roles for activin-like kinase-2 signaling during mouse embryogenesis. Dev Biol. 213(2), 314-326.

161. Seo, S. and Kume, T. (2006). Forkhead transcription factors, Foxc1 and Foxc2, are required for the morphogenesis of the cardiac outflow tract. Dev Biol. 296(2), 421-436.

162. Firulli, A.B., McFadden, D.G., Lin, Q., Srivastava, D., and Olson, E.N. (1998). Heart and extra-embryonic mesodermal defects in mouse embryos lacking the bHLH transcription factor Hand1. Nat Genet. 18(3), 266-270.

163. Srivastava, D., Thomas, T., Lin, Q., Kirby, M.L., Brown, D., and Olson, E.N. (1997). Regulation of cardiac mesodermal and neural crest development by the bHLH transcription factor, dHAND. Nat Genet. 16(2), 154-160.

164. Carmeliet, P., Ng, Y.S., Nuyens, D., Theilmeier, G., Brusselmans, K., Cornelissen, I, Ehler, E., Kakkar, V.V., Stalmans, I., Mattot, V., Perriard, J.C., Dewerchin, M., Flameng, W., Nagy, A., Lupu, F., Moons, L., Collen, D., D'Amore, P.A., Shima, D.T. (1999). Impaired myocardial angiogenesis and ischemic cardiomyopathy in mice lacking the vascular endothelial growth factor isoforms VEGF164 and VEGF188. Nat Med. 5(5), 495-502.

165. Kawasaki, T., Kitsukawa, T., Bekku, Y., Matsuda, Y., Sanbo, M., Yagi, T., and Fujisawa, H. (1999). A requirement for neuropilin-1 in embryonic vessel formation. Development. 126(21), 4895-4902.

166. Bi, W., Drake, C.J., and Schwarz, J.J. (1999). The transcription factor MEF2C-null mouse exhibits complex vascular malformations and reduced cardiac expression of angiopoietin 1 and VEGF. Dev Biol. 211(2), 255-267.

167. Kitamura, K., Miura, H., Miyagawa-Tomita, S., Yanazawa, M., Katoh-Fukui, Y., Suzuki, R., Ohuchi, H., Suehiro, A., Motegi, Y., Nakahara, Y., Kondo, S., and Yokoyama, M. (1999). Mouse Pitx2 deficiency leads to anomalies of the ventral body wall, heart, and extra- and periocular mesoderm and right pulmonary isomerism. Development 126(24), 5749-5758.

168. Zhang, P., Liegeois, N.J., Wong, C., Finegold, M., Hou, H., Thompson, J.C., Silverman, A., Harper, J.W., DePinho, R.A., and Elledge, S.J. (1997). Altered cell differentiation and proliferation in mice lacking p57KIP2 indicates a role in Beckwith-Wiedemann syndrome. Nature. 387(6629), 151-158.

169. Yan, Y., Frisen, J., Lee, M.H., Massague, J., and Barbacid, M. (1997). Ablation of the CDK inhibitor p57Kip2 results in increased apoptosis and delayed differentiation during mouse development. Genes Dev. 11(8), 973-983.

170. Kirby, M.L. (2007). Cardiac Development. Oxford University Press.

\section{This article should be cited as follows:}

Snider, P., Olaopa, M., Firulli, A.B., and Conway, S.J. (2007) Cardiovascular development and the colonizing cardiac neural crest lineage. TSW Development \& Embryology 2, 88-111. DOI 10.1100/tswde.2007.160. 


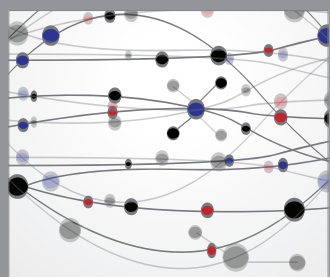

The Scientific World Journal
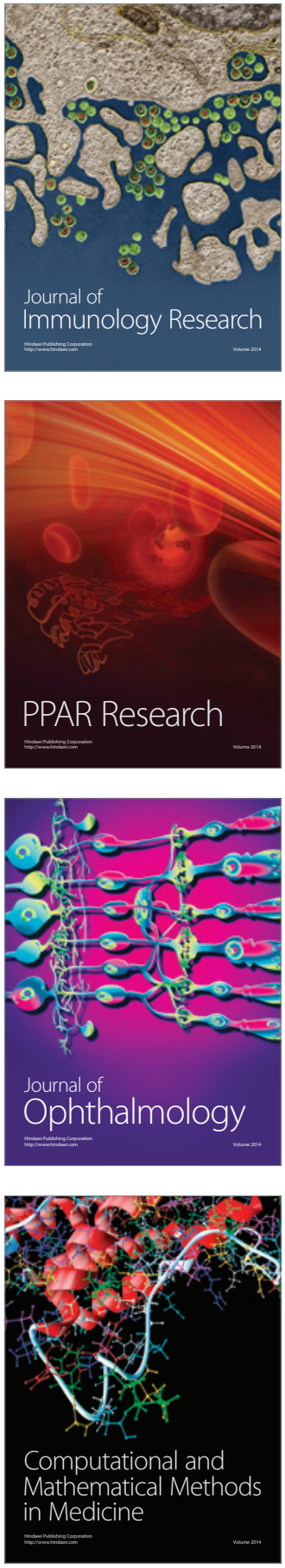

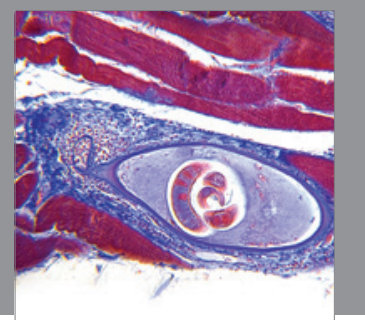

Gastroenterology

Research and Practice
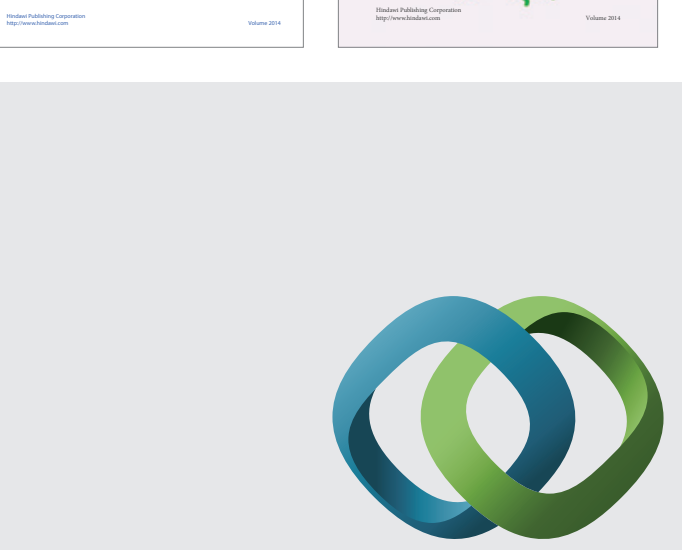

\section{Hindawi}

Submit your manuscripts at

http://www.hindawi.com
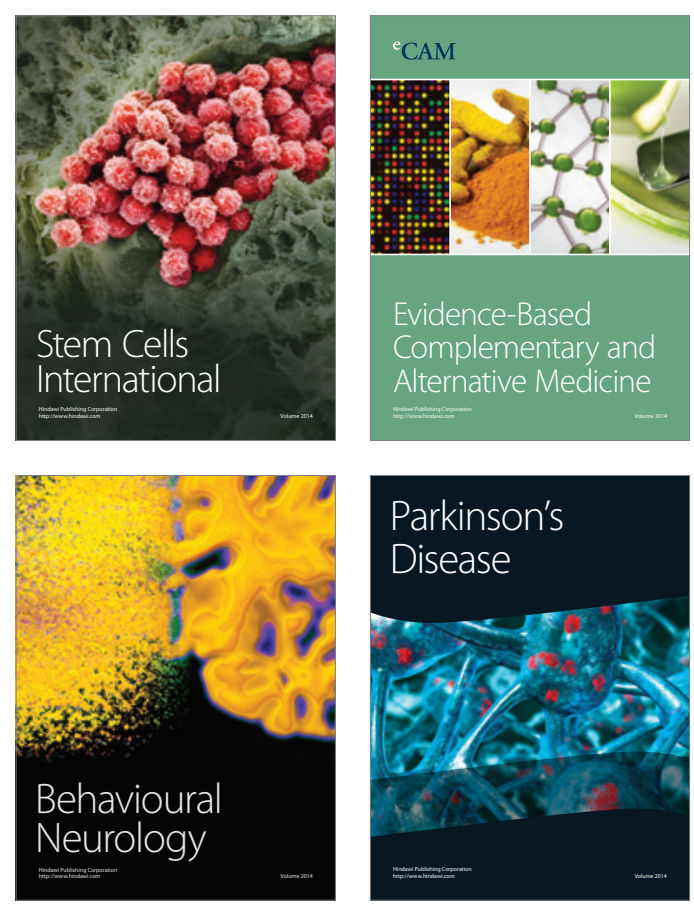

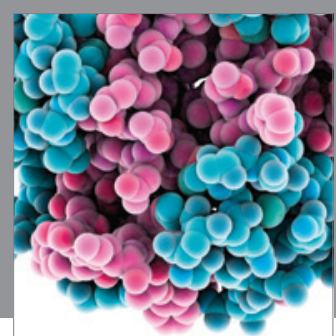

Journal of
Diabetes Research

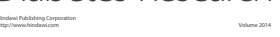

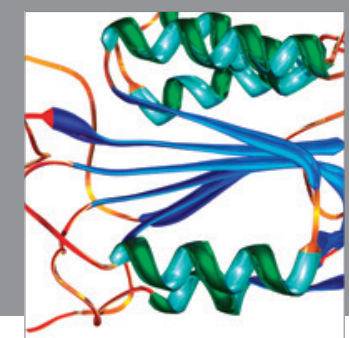

Disease Markers
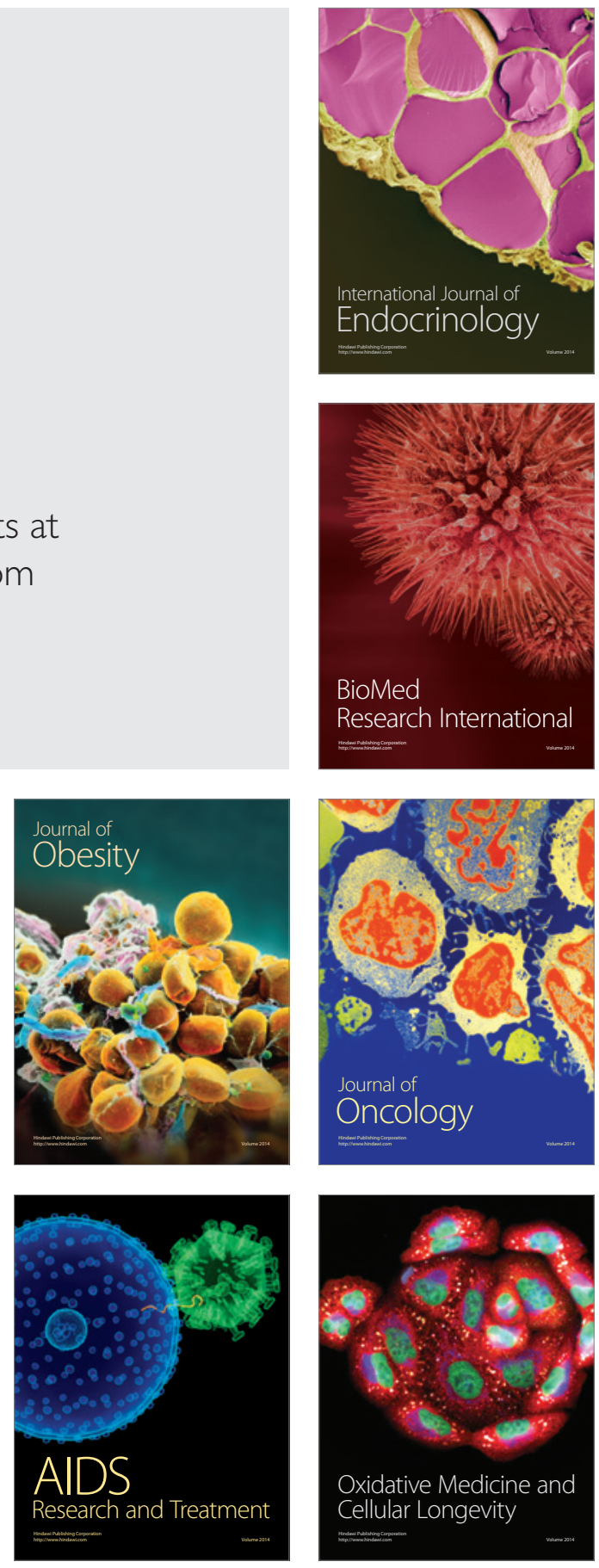